\title{
Stress-Dependent Permeability of Fractured Rock Masses: A Numerical Study
}

Ki-Bok Min ${ }^{* 1}$, J Rutqvist ${ }^{2}$, Chin-Fu Tsang ${ }^{2}$, and Lanru Jing ${ }^{1}$

${ }^{1}$ Engineering Geology and Geophysics Research Group, Royal Institute of Technology (KTH), Stockholm, Sweden

${ }^{2}$ Earth Sciences Division, Lawrence Berkeley National Laboratory (LBNL), Berkeley, CA, USA

* corresponding author. Tel.: +46-8-790-7919; fax: +46-8-790-6810.

E-mail address: kibok@kth.se (Ki-Bok Min) 


\section{Abstract}

We investigate the stress-dependent permeability issue in fractured rock masses considering the effects of nonlinear normal deformation and shear dilation of fractures using a two-dimensional distinct element method program, UDEC, based on a realistic discrete fracture network realization. A series of "numerical" experiments were conducted to calculate changes in the permeability of simulated fractured rock masses under various loading conditions. Numerical experiments were conducted in two ways: (1) increasing the overall stresses with a fixed ratio of horizontal to vertical stresses components; and (2) increasing the differential stresses (i.e., the difference between the horizontal and vertical stresses) while keeping the magnitude of vertical stress constant.

These numerical experiments show that the permeability of fractured rocks decreases with increased stress magnitudes when the stress ratio is not large enough to cause shear dilation of fractures, whereas permeability increases with increased stress when the stress ratio is large enough. Permeability changes at low stress levels are more sensitive than at high stress levels due to the nonlinear fracture normal stress-displacement relation. Significant stress-induced channeling is observed as the shear dilation causes the concentration of fluid flow along connected shear fractures. Anisotropy of permeability emerges with the increase of differential stresses, and this anisotropy can become more prominent with the influence of shear dilation and localized flow paths. A set of empirical equations in closed-form, accounting for both normal closure and shear dilation of the fractures, is proposed to model the stress-dependent permeability. These equations prove to be in good agreement with the results obtained from our numerical experiments. 


\section{Introduction}

Hydro-mechanical coupling in fractured rock masses is an important issue for many rock mechanics and hydrogeology applications [1]. Fractured rock masses are composed of intact rock materials and fractures, with the latter acting as the main pathways of fluid flow, especially in hard rocks. Apertures of fractures can change due to normal stress-induced closures or openings and due to shear stress-induced dilations. Hence, the permeability of fractured rock masses is stress-dependent. This process can be viewed as an "indirect" hydro-mechanical coupling that occurs when the applied stresses produce a change in the hydraulic properties, whereas a "direct" coupling occurs when the applied stresses produce a change in fluid pressure and vice versa [1]. This indirect coupling is particularly important in fractured rock masses, since stress-induced changes in permeability can be large (several orders of magnitude) and irreversible under perturbations resulting from various natural and human activities. These activities include underground constructions causing stress redistributions close to the openings, geothermal energy and oil/gas reservoir productions where injections and extractions of fluids entail significant changes in effective stresses underground. In particular, the stress-dependent permeability plays an important role in the performance assessment of nuclear waste repositories within geological formations, since geological media may undergo complex stress-deformation paths from various sources of perturbations, including excavations, expansion of buffer materials, thermal loading/unloading from the heat-generating nuclear waste decay and climate-related phenomena such as glaciation cycles. Therefore, the influence of stresses on permeability should be properly investigated.

Laboratory investigations on single rock fractures show that normal closure and shear dilation can significantly change fracture transmissivity $[2,3]$. When it comes to a fracture system that contains a multitude of fractures, the changes in the transmissivities of critically oriented fractures can be 
much higher than that of other fractures not critically (optimally) oriented for shear failure [4]. These observations are supported, for example, by work described in [5], where the concept is applied to geothermal reservoirs to detect flow pathways. Regarding the effect of redistributed stresses, a number of studies have been conducted about the permeability alterations around the excavated openings [6,7]. They considered blast damage and fracture closures/openings from stress-relief as the main sources of permeability alteration, without considering shear dilations of fractures. In addition, a disturbed zone can be generated around the excavated openings [8], and fracture dilations in this zone can also be a source of permeability change. A study based on an orthogonal fracture system geometry [9] shows that the extent of the disturbed zone can be significant, depending on the fracture system geometry and the in situ stress conditions.

A study of the excavation-disturbed zone at the Äspö Hard Rock Laboratory in Sweden showed that transmissivities of the fractures around a tunnel sometimes increased and sometimes decreased as a result of excavation, and it was not possible to make a firm statement about how to model the change in fracture transmissivity [10]. The difficulty is mainly in how to represent the complex fracture system geometry, with various orientations and finite sizes of fractures, and how to represent the complex mechanical deformation mechanisms that are much influenced by the interactions between individual fractures.

Analytical models of stress-dependent permeability of fractured rock masses based on orthogonal or persistent fractures sets are available [11-13] that consider the normal closures of fractures and constant shear dilations in both fractured and fractured-porous media. However, models based on persistent fractures have certain limitations in simulating the abrupt shear dilations and highly clustered flow paths resulting from stress changes. Oda's permeability tensor approach considers stress-dependency in complex fracture networks [14]. However, fracture connectivity and complex 
fracture interactions, which are important factors affecting the overall hydro-mechanical behavior of the fractured rock masses, cannot be considered in this approach. Especially, when the shear failures and dilations of fractures are to be considered, analytical solutions do not exist. Therefore, numerical modeling has to be applied to deepen the understanding of the critical mechanisms and the contributions to the overall permeability from both normal and shear stresses $[15,16]$.

Work by Zhang and Sanderson shows that the method of 'numerical experiment' using the distinct element code, UDEC (Universal Distinct Element Code, [17]) is effective in modeling fluid flow and deformation of fractured rock masses [18]. The influence of stresses on permeability of fractured rock masses was extensively investigated considering various geometries of fracture systems [19-21]. Such numerical experiments will be increasingly important with the advance of computing capacity due to the strength of distinct element modeling that can incorporate both hydraulic and mechanical analysis with explicit representation of fractures.

The present paper goes beyond the work of Zhang and Sanderson by requiring that the following three conditions must be satisfied.

- Firstly, the model size for the numerical experiments should be properly established so that the initial mechanical and hydraulic behavior of the model are statistically representative. This means that the mechanical and hydraulic REVs (representative elementary volume) of the numerical model must be reached $[22,23]$, before modeling hydraulic behaviour with stress effects.

- Secondly, the normal stress-displacement relation of fractures should be realistically represented because of the significant role of fracture aperture changes on the overall permeability of the rock mass concerned. Laboratory tests prove that the normal stress-displacement behavior of 
fractures is highly nonlinear (e.g. $[24,25])$ and this feature has to be considered for accurate prediction of permeability change due to stress effect. A linear relation between normal stress and fracture closure (therefore constant normal stiffness) will not be able to serve the purpose since it generally underestimates the change of fracture transmissivity at lower normal stress magnitudes.

- Thirdly, shear dilations caused by the roughness of fracture surface should be modeled since the effect of fracture dilation on permeability is significant $[16,26]$. The assumption of zero dilation (therefore assuming smooth fracture surfaces) in the fracture models will not only lead to underestimated fracture tranmissivity change in general, but also lose the capability of explaining the clustered fluid flow phenomenon associated with critically-stressed fractures, often observed in fractured rock masses [4].

As far as we know, the above three aspects were not considered, at least not systematically, in the previous studies of numerical experiments for stress-dependent permeability of fractured rock masses, including those reported in [18-21].

The objective of this paper is then to investigate the stress-dependent permeability in fractured rock masses considering the realistic representation of fracture system geometry and stress-deformation behavior based on the above considerations. The geometrical basis for this study is a discrete fracture network (DFN) generated in a square region, $5 \mathrm{~m} \times 5 \mathrm{~m}$ in size, based on statistical information of fractures from a site characterization programme at Sellafield, England [27]. The size of $5 \mathrm{~m} \times 5 \mathrm{~m}$ is selected for the model based on the previous investigations for the calculations of the equivalent mechanical and hydraulic properties and this scale was proven to represent both the initial mechanical and hydraulic REVs [22, 23]. A step-wise normal stiffness model of fracture is implemented to represent the normal stress-normal closure deformation response and special emphasis is given to the role of fracture shear dilation and associated channeling of flow for the 
investigation of stress-dependent permeability, adopting an elasto-perfectly plastic shear behaviour for the fracture. A series of numerical experiments was conducted using various stress conditions for calculating the corresponding flow fields and changes in the permeability of the region. Results for fluid flow under various stress conditions suggest a phenomenon of stress-induced flow channeling and permeability anisotropy, and provide an insight into the factors controlling the stress-permeability interactions. Finally, a set of empirical relations in closed-form is proposed for a more general description of stress-dependent permeability, which can be implemented as a part of constitutive models of fractured rocks into continuum-based numerical codes for solving coupled hydro-mechanical problems of fractured rocks or can be used directly for different site characterization applications.

\section{Fracture Deformations and Stress-Induced Permeability Change}

Figure 1 presents the basic mechanisms of aperture changes resulting from two basic fracture deformations as observed in numerous laboratory experiments and the states of stress on fractures. The change in fracture aperture occurs from two basic mechanisms: normal stress-induced closure or opening, and shear stress-induced dilation. In normal stress-displacement relation (Figure 1a), the response shows the well-known hyperbolic behavior showing stiffer fractures with increasing compressive normal stresses. The normal deformation of a fracture is more sensitive at lower magnitudes of normal stresses. The shear dilation occurs as a result of overriding asperities of two rough fracture surfaces and may reach a stationary value with increasing fracture shearing (Figure 1b). Such shear dilation of fractures is of particular importance, since its magnitude can be significantly larger than the normal stress-induced closure or opening.

When a multitude of fractures needs to be considered (i.e., in fractured rock masses), the fact that not all the fractures are under the same stress conditions should be properly considered (Figure 1c). 
Firstly, the orientations of fractures play a significant role in deciding the local stress states across and along the fractures, which can be represented using the Mohr circles, as shown in Figure 1d. The different stress states of fractures with different orientations, therefore, lead to different directional hydraulic behavior of the fractured rock masses. Secondly, when fractures have finite sizes and interact with each other, the estimation of local stress by Mohr's circle is not valid any more and detailed local stress states can only be analyzed by numerical analysis such as distinct element methods (DEM) used in this study. It is noted that the fractures modeled in this study are assumed to maintain the contact along the surfaces based on the understanding that the scale of geometric irregularity along the surface of fracture is small compared to the scale of the entire fracture. However, when there is an open fracture (with or without the fluid in it), i.e. the scale of irregularity of surface is big compared to the scale of fracture, the assumption of maintenance of contact will not be valid. When there is no fluid in the open fracture, no stress will be transmitted across the fracture and, when there is fluid in it, shear stress cannot be transmitted across the fracture. Therefore, the stress distribution around the open fracture can be different. This aspect can be considered by more explicit representation of void shape of fractures, however, this is not the scope of this study.

When the stress ratio, defined as the ratio of the maximum to minimum principal stresses in two dimensions, is too small to cause shear failure of fractures, the normal stresses will be the main source of aperture changes, leading to a general decrease of permeability of rock masses. However, when the stress ratio is large enough to cause shear failure at the critically oriented fractures, the shear dilations of these fractures can cause significant increase in their apertures, while the other less critically oriented fractures still undergo mainly normal displacements caused by normal stresses. Such non-uniformly distributed apertures may lead to changes in fracture flow paths and permeability of the region concerned. 
Based on this conceptualization of stress-aperture interaction in fractured rocks, the stress-loading conditions for this study are selected in two ways (Figure 2). Firstly, horizontal and vertical compressive stresses are applied and increased incrementally, with a fixed ratio of horizontal to vertical boundary stresses, $\mathrm{k}=1.3$, based on the data provided from the Sellafield site [27]. It is expected that no significant shear dilation will occur under this stress condition and the effect of normal stress conditions on the overall fluid flow field and permeability of the region can be simulated. Secondly, the horizontal normal boundary stress is increased incrementally while keeping the vertical normal stress constant, thus to produce increased shear stresses in the fractures, especially those with critical orientations. Through this process, the impact of shear dilations of critically oriented fractures, with the resulting effect on the overall permeability, can be investigated for both pre- and post-shear failure conditions of fractures.

\section{Procedure for Numerical Experiments}

The two-dimensional distinct element code, UDEC [17] is used for modeling the mechanical and hydraulic behavior of a fractured rock masses. UDEC represents a fractured rock masses as an assemblage of discrete blocks and fractures that define the block system geometry. The numerical experiments consist of (1) generation of a DFN as a geometric model, (2) application of various stress conditions to generate deformed states of the DFN model, and (3) application of fluid boundary conditions to the deformed DFN model and calculation of the overall permeability.

\subsection{Generation of DFN}

A realistic DFN is generated as one of multiple realizations by Monte Carlo simulations [22]. Figure 3 shows the DFN model used in this study. Fracture-system statistics data for this analysis are taken from the result of site investigation at Sellafield undertaken by Nirex, UK (Table 1). Four fracture sets were identified, and their orientations were found to have near-random patterns owing 
to their low Fisher constants. The orientations in three-dimensional form were converted to twodimensional form by calculating the apparent dip along the reference plane [27].

The fracture trace lengths are characterized by a power law, as follows:

$$
N=4 \times L^{-2.2}
$$

where $\mathrm{N}$ is the number of fractures with lengths longer than a given fracture length $L(\mathrm{~m})$ per unit

area $\left(\mathrm{m}^{2}\right)$. The minimum and maximum cut-off trace lengths were chosen as $0.5 \mathrm{~m}$ and $250 \mathrm{~m}$, respectively.

\subsection{Application of Boundary Stresses}

After the generation of the DFN model, various boundary stresses were applied to generate deformed models for flow analysis. The boundary stresses were selected in two ways, as described above. Each rock block in between fractures was modeled as continuous, homogeneous, isotropic, linear, elastic and impermeable media and subdivided with a mesh of constant-strain triangle finitedifference elements. Key factors affecting the hydraulic behavior of fractures, such as opening, closure, sliding and dilation, were modeled by incorporating relevant fracture constitutive models. A step-wise nonlinear normal stress-normal closure relation is adopted to approximate a hyperbolic normal deformation process (Figure 4). The shear stress-shear displacement fracture behavior was modeled by an elasto-perfectly plastic constitutive model with a Mohr-Coulomb failure criterion and fracture dilation occurs when it starts to slide (Figure 5). This dilation continues until a predefined critical shear displacement $\left(U_{c s}\right)$ value beyond which the dilation stops. 
Necessary model parameters are listed in Table 2. These parameters, however, were chosen to demonstrate the significance of stress-flow behavior in the model concerned and do not necessarily reflect the in situ conditions at Sellafield. The most important parameter for the evaluation of stressdependent permeability is the fracture aperture value, and its evolution with the stress-deformation paths and history. In this study, the residual aperture was set to be $5 \mu \mathrm{m}$, the initial aperture $30 \mu \mathrm{m}$, and the maximum aperture $50 \mu \mathrm{m}$, respectively, largely based on four laboratory experiments [27]. The fractures were characterized with low JRC (Joint Roughness Coefficient) values (3.85), which made the range of aperture closure change only a factor of six from their initial states. In this study, no efforts were made to distinguish the hydraulic and mechanical apertures and the dilation angle is assumed to be constant irrespective of stress levels for simplicity. While mechanical aperture is the one measured geometrically, hydraulic aperture is the one calculated from the flow tests assuming the smooth wall of fractures and, therefore, hydraulic aperture is lower than mechanical aperture [3]. According to the exponential equation suggested by Barton [3] relating the hydraulic aperture to the mechanical aperture and JRC during the normal closure of fracture, the range of mechanical aperture from $5 \mu \mathrm{m}$ to $30 \mu \mathrm{m}$ corresponds to about $1 \mu \mathrm{m}$ to $30 \mu \mathrm{m}$ of hydraulic aperture. Therefore, the assumption of equating the hydraulic aperture with mechanical aperture in this study could underestimate the permeability decrease due to the fracture closure. For the shear dilation of fractures, the relation between the hydraulic and mechanical aperture needs more experiment for the proper estabilshment [3] and the values of maximum aperture $(50 \mu \mathrm{m})$ is taken from the maximum hydraulic aperture during shear experiments in order to properly consider the consequence of permeability change in the DFN model.

\subsection{Calculation of Equivalent Permeability}

Equivalent permeability of the model region was calculated under various stress conditions, with the corresponding changes of fracture apertures after the application of stresses (Figure 6). The fluid 
flow takes place in fractures only and was calculated by the cubic law. Mass conservation of fluid was assured at each fracture intersection and in the domains between them.

The $\mathrm{x}$ - and y-directional permeabilities were calculated with a specified hydraulic pressure gradient on boundaries in $\mathrm{x}$ and $\mathrm{y}$-directions, respectively, and no-flow lateral boundaries (Figure 6). Calculations were made with the following equation, assuming no gravity term:

$$
Q_{x}=A \frac{k_{x}}{\mu} \frac{\partial P}{\partial x}, Q_{y}=A \frac{k_{y}}{\mu} \frac{\partial P}{\partial y}
$$

where $Q_{x}$ and $Q_{y}=$ the flow rates in the $\mathrm{x}$ and y directions at the boundaries, respectively; $A=$ the cross-sectional area; $k_{x}$ and $k_{y}=$ the permeability in the $\mathrm{x}$ and $\mathrm{y}$ directions, respectively; $\mu=$ the dynamic viscosity; and $P=$ the hydraulic pressure. In the numerical simulations, all terms on the right-hand side of Equation (2), except for $k_{x}$ and $k_{y}$, are specified, and $Q_{x}$ and $Q_{\mathrm{y}}$ are calculated numerically. Then, $k_{x}$ and $k_{y}$ are back-calculated using Equation (2).

\section{Permeability Change as a Function of Stress Change with a Fixed Stress Ratio}

Here we present the results from incremental increase of both horizontal and vertical boundary stresses while keeping a constant stress ratio of 1.3 between them. Because the stress ratio is close to unity, the stress states in most of the fractures do not cause shear failure, and normal stress is the main cause for the aperture change, basically closure.

Figure 7 shows the aperture changes with the increase of boundary stresses. The initial aperture ( 30 $\mu \mathrm{m})$ at a zero stress level decreased to $8.8 \mu \mathrm{m}$ (mean values) when the mean stress magnitude was increased to $23 \mathrm{MPa}$. The changes of fracture apertures occur almost uniformly within the model region with the increase of stresses. This is because the fracture normal closure resulting from 
normal stress increases is the dominating mechanism that controls fracture deformation, since significant shear dilation does not occur with the stress ratio equal to 1.3. Aperture anomalies can be observed in a few isolated places in the model region, mainly in the sharp corners of the blocks where fracture failure occurs due to the stress concentration. However, these were observed only locally without being extended to entire fracture length and therefore, their influence on the overall fluid flow field is minor for this two-dimensional analysis.

Figure 8 shows the calculated equivalent permeability change with the increases in mean stresses. Because of the dominating fracture closure with the increasing normal stresses, the permeability of the model decreases accordingly. The reduction of permeability is more than two orders of magnitude, and anisotropy in permeability is not significant, mainly because the stress ratio $\mathrm{k}$ is close to an isotropic boundary stress condition. This result is comparable to the permeability variation with depth reported in [29] with the depth corresponding to stress changes. Similar numerical results in $[19,20]$ with constant normal stiffness of fracture also showed the decrease of permeability corresponding to the increase of stresses. However, the application of the non-linear normal stiffness of fractures in the fracture model in this study led to more sensitive responses of permeability change at lower normal stress magnitudes, and the permeability change becomes small when the stress reaches the laboratory level of residual stress $(30 \mathrm{MPa})$ of fractures. This implies that permeability in shallow depth is more sensitive to that in greater depth as was reported in [1].

It would be interesting to consider the effect of tension on the permeability change, which means the extension of the curve in Figure 8 to the left into the tensile region. Since the stiffness of rock fracture under tension is negligible, the change of permeability increase caused by tension will be dramatic. This dramatic effect can have significance in engineering applications, e.g., hydraulic fracturing and such dramatic increase of permeability due to the tension of fracture are reported in 
[30] for geothermal energy application under the relatively high in situ stress conditions (20 MPa). It showed that the stress drop by cooling caused by the temperature difference between the rock and injected fluid can cause drastic increase of permeability when the temperature difference is larger than a critical value that can induce the tension of fractures.

To characterize the flow pattern changes with respect to the stress changes, normalized flow rates at the left boundary of the model are plotted in Figure 9. Flow rates without stresses (Figure 9a) are almost uniform without dominance by a few fractures. This is because the initial apertures in all fractures are set to be identical $(30 \mu \mathrm{m})$. The results from Figure $9 \mathrm{~b}$ to Figure $9 \mathrm{f}$ show that the changes in flow-rate patterns are negligible, despite the stress increase, because the normal fracture closures occur almost uniformly, as shown in Figure 7. Fluid flow only changes quantitatively; it does not change its basic overall pattern.

\section{Permeability Change as a Function of Increasing stress ratio}

In this section, we present the results when the horizontal boundary stress is increased in steps from 2.5 $\mathrm{MPa}$ to $25 \mathrm{MPa}$, with a fixed vertical boundary stress of $5 \mathrm{MPa}$ (the k ratio changing from 0.5 to 5), to investigate the influence of shear failure in fractures induced by larger differential stresses.

Figure 10 shows the aperture changes with the increasing stress ratio. In contrast to Figure 7 , fracture aperture changes are not uniform. At the stress ratio of 3.0, large apertures can be observed in the critically oriented and well-connected fractures, affecting therefore the flow paths significantly. This tendency becomes increasingly clear at the stress ratio of 5 . An examination of the results suggests the following reasons for this phenomenon:

- Critically oriented fractures continue to dilate under increasing differential stresses, which leads to much larger apertures of these fractures compared to their less critically oriented neighboring fractures. In this study, the critical orientation is the orientation that is prone to 
shear failure due to the applied stresses: it is calculated as about 33 degrees by the Eq. (11) defined in the next section with the friction angle of 24.9 degrees set for this study.

- It is not only the orientation of fractures but also the connectivity of fractures that is needed for the formation of sufficient fracture dilation by stress change. Because the neighboring fractures can hinder further plastic shear development in fractures of critical orientation, many critically oriented fractures with poor connectivity could not produce large apertures, on account of their poor connection to the fractures with similar orientation.

- The trace length of fractures is another important factor in forming clustered fractures conducting fluid flow with large apertures. This is natural with respect to connectivity, since longer fractures have a higher degree of connectivity compared to short ones, which are prone to being hindered by the neighboring fractures and rock blocks. The figure shows that the long fractures are much more dilated than the shorter fractures (among the critically oriented fractures), which is also in line with field observations (e.g., [31]).

Figure 11 presents the calculated equivalent-permeability changes with the increasing $\mathrm{k}$ ratio. To evaluate the effect of shear dilation, we compared the results with a pure elastic fracture model that excludes failure and dilation (the dashed lines in Figure 11). The pure elastic and the elastoplastic models show a similar response until the stress ratio $\mathrm{k}$ reaches approximately 2.5 . This stress ratio agrees well with the critical stress ratio (2.45) estimated by the analytical equation (calculated from Equation (10) in the next section) and it is the starting point of shear failure for fractures inclined at about 33 degrees from the horizontal plane. At this point and afterwards, some fractures in the fractured rock masses start to fail and, with continued shear dilation, notable differences between the models are observed. At stress ratio $\mathrm{k}=5$, the additional contribution from shear dilations of fractures is more than one order of magnitude for $\mathrm{k}_{\mathrm{x}}$ and a factor of four for $\mathrm{k}_{\mathrm{y}}$. On the other hand, the fractures that are not critically oriented continue to close with an increase in stresses, and this 
makes their apertures smaller and reduced fluid flow. However, the dilation of fractures caused by shear is abrupt (with larger gradients) when shear failure starts to develop, and this dominates the process. As the horizontal boundary stress increases, the range of fracture orientation angles for possible shear failure also increases, with resulting increased permeability. The increase of permeability stabilizes after a certain $\mathrm{k}$ ratio, because the shear dilation of a fracture does not continue after their critical shear displacement is reached. Interestingly, this increased permeability is analogous to experimental results on the intact rocks, which show a similar decrease and increase in permeability with increasing differential stresses [32].

A similar type of sudden increase of permeability at critical stress state was shown in [21] with three types of fractured rocks. In their models, change of permeability was insensitive to differential stress before the critical stress ratio was reached because the differential stress was increased while maintaining the same mean stress. Despite the insightful illumination regarding abrupt increase of permeability in [21], the mechanical REV issue was not considered, which could make the mechanical behavior less representative and shear displacement overestimated. The other previous studies in $[19,20]$ did not show such sudden increase of permeability because the dilation mechanisms are not modeled. Permeability continued to decrease with the increase of stress ratio up to 8 when zero dilation angle was used and stress ratio up to 9 when a high cohesion (1.8 MPa) was used as an input for fracture parameter compared to the minimum principal stress (1 MPa), which could not capture the dilation behavior [20, 19].

With the increase in horizontal stress, the anisotropy for the equivalent permeability of the model also becomes significant (Figure 12). This is because the subvertical fractures are more vulnerable to closure by the horizontal stresses, and its effect on the x-directional permeability of the model is more pronounced. The ratio of anisotropic permeability, defined as $k_{x} / k_{y}$, increased from about 0.5 to 2 with the increase of stress ratio $\mathrm{k}$ from 0.5 to 2.5 . When dilation starts, anisotropy becomes much more significant, and the maximum anisotropy ratio reaches approximately 8 . The fracture 
network used in this study shows a near-random fracture pattern with slightly more vertical fractures. The change of anisotropic permeability during the increase in differential stresses could be more drastic if the model had more fractures of critical or near-critical orientations for shear failure.

Figure 13 shows the change in flow patterns with the increasing stress ratio. A notable channeling flow effect caused by stress-induced fracture dilation is observed, analogous to the channeling effect observed in fractured rock as reported in [33]. The stress-induced channeling has a number of possible explanations. As large shear dilations are concentrated in a smaller part of the fracture population with near-critical orientations, good connectivity, and long trace lengths, the rest of the fracture population, especially the subvertical ones, still undergo the normal closures without any shear dilation. This situation causes a high contrast in aperture values between the fractures. Therefore, a few fractures with much increased apertures become the major pathways of localized fluid flow. The dilated fractures tend to be those inclined more horizontally with the increasing horizontal stress, and this tendency makes the channeling effect with horizontal hydraulic pressure gradient (Figure 13a) more manifest than the vertical pressure gradient (Figure $13 \mathrm{~b}$ ). The localized flow patterns generated from these numerical experiments are often observed in the field. It is now well known that only a portion of fractures dominate the flow behavior of the interested area in fractured hard rock (e.g., [4]). The observation in the Sellafield area also shows that hydraulically active fractures are a small subset of all fractures, and that they tended to be spatially clumped [27]. The effect of differential stresses may provide one of the possible reasons for the observed clustered fluid flow in the fractured rocks, since the distributed permeability at present in the field is, in fact, the result of past and ongoing geological processes (such as tectonic movements), with consequences in stress states. The other possible reasons include, of course, the differences in aperture values, the effect of connectivity of fracture systems and chemical effects in the fractures. 
Figure 14 shows the normalized flow rates in each fracture intersecting the left vertical boundary of the model. The initial uniform flow pattern abruptly changes when fracture dilation starts to develop, at a stress ratio of about 3 and beyond. Only $10 \%$ of fractures (four out of 40 fractures) carry about $50 \%, 65 \%$ and $70 \%$ of the fluid flow across the boundary, at a stress ratio of 3, 4, and 5, respectively — which demonstrate the channeling effect induced by stresses. In order to provide a more quantified illumination of channeling induced by shear dilation, the normalized maximum flows are plotted with the increase of stress ratio (Figure 15). After the critical stress ratio, the value abruptly increases and maintains a certain level beyond the critical stress ratio. Relatively lower value at stress ratio 3.5 was caused by the transition of the location of most conducting fractures from stress ratio 3.0 to 4.0, as can be observed in Figure 14 (d) and Figure 14 (e).

\section{An Empirical Equation for Stress-Dependent Permeability}

\subsection{Construction of the Empirical Equation}

We develop a set of empirical equations for the stress-dependent permeability that incorporates the effects of both normal closure and shear dilation of fractures (Figure 16), in order that more comprehensive constitutive models of fractured rocks can be developed for analysis of coupled hydro-mechanical processes. In this equation, the permeability changes from normal and shear stresses are considered independently and final permeability $\left(k_{x}, k_{y}\right)$ is calculated by superimposing the permeability from shear stress-induced dilation $\left(k_{d x}, k_{d y}\right)$ and normal stress-induced closure or opening $\left(k_{n x}, k_{n y}\right)$ of fractures. Associated parameters for the equation can be obtained from laboratory and numerical experiments. The difference between the proposed equation and previous ones [11-14] is that (1) more general DFN representation of fracture system is used as the geometrical basis, (2) numerical experiments using the DEM approach are employed as the 
platform for deriving the stress-permeability relation, and (3) stress-induced channeling of flow caused by shear dilation can be more effectively considered.

When the model has orthogonal and persistent fracture sets with the same spacing and the same apertures values, the equivalent permeability component (for instance in the x-direction) can be modeled as follows (adapted from [34]):

$$
k_{x}=\frac{f}{12} b^{3}
$$

where $k_{x}$ is the permeability in $\mathrm{x}$ direction, $f$ is the fracture frequency in the model, and $b$ is the aperture of the fractures.

In DFN, however, a single frequency cannot be defined due to the multiple sets of fractures with finite sizes and a single aperture cannot be defined due to varied aperture values in each fracture. Therefore, the concepts of "equivalent frequency $\left(f_{x}, f_{y}\right)$ " and "equivalent aperture $\left(b_{x}, b_{y}\right)$ " are employed here in order to approximate the complex fracture deformation of DFN model in a simple form. Using these equivalent frequencies and apertures, the permeability from normal closure or opening in $\mathrm{x}$ - and $\mathrm{y}$-directions $\left(k_{n x}, k_{n y}\right)$ may be formulated as follows.

$$
\begin{aligned}
& k_{n x}=\frac{f_{x}}{12} b_{x}{ }^{3} \\
& k_{n y}=\frac{f_{y}}{12} b_{y}{ }^{3}
\end{aligned}
$$

The concept of equivalent frequency is presented in Figure 17. The equivalent aperture is meant to be the representative value of all fractures in the DFN model, which means that one single value is 
used for representing the apertures of entire DFN model to approximate the hydraulic behaviour of DFN model with the cubic law shown in Eq.(4). Because uniform normal closures occur with respect to a certain stress condition, as was observed from the numerical experiments (Figure 7 , Figure 9), it may be possible to use this kind of 'collective' equivalent aperture for the stressdependent permeability, once the relevant frequency is determined.

Equivalent frequency can be back-calculated from the numerical experiments with initial apertures by the following relation:

$$
f_{x}=\frac{12 k_{n x}}{b_{i}^{3}}
$$

where $b_{i}$ is the initial mean aperture. Since initial aperture is known (30 $\mu \mathrm{m}$ in this study) and $k_{n x}$ is calculated from the numerical experiments, the equivalent frequency in x-direction can be calculated. Similarly the equivalent frequency in the y-direction can be calculated as follows:

$$
f_{y}=\frac{12 k_{n y}}{b_{i}^{3}}
$$

The following form of aperture and stress relation with residual hydraulic aperture $\left(b_{r}\right)$ and maximum deformation of fracture $\left(b_{\max }\right)$ was proposed in [35]

$$
b=b_{r}+b_{m}=b_{r}+b_{\max } \exp \left(-\alpha^{\prime} \sigma\right)
$$


where $\alpha^{\prime}$ is a parameter related to the curvature of the function relating normal closure with normal displacement, and $\sigma$ is the normal stress across the fracture with the compressive stresses positive. From this equation, the initial aperture at zero stress level $\left(b_{i}\right)$ is given by summation of $b_{r}$ and $b_{\max }$.

The basic form for the one-dimensional case in Equation (6) is extended to two dimensions, and the equivalent total normal closure in the $\mathrm{x}$-direction $\left(b_{x}\right)$ is defined by the following relations considering two-dimensional stress state:

$$
b_{x}=b_{r}+b_{m}=b_{r}+b_{\max } \exp \left\{-\left(\alpha_{x} \sigma_{x}+\alpha_{y} \sigma_{y}\right)\right\}
$$

where $\sigma_{x}$ and $\sigma_{y}$ are the normal stresses in x- and y-directions, respectively and $\alpha_{x}$ and $\alpha_{y}$ are the coefficients for the fracture closure in x-direction under the normal stresses $\sigma_{x}$ and $\sigma_{y}$, respectively. These coefficients are related to the sensitivity of the normal displacement responses to the normal stresses and the orientation of fractures.

Similarly, equivalent normal closure in y-direction $\left(b_{y}\right)$ can also be defined as follows:

$$
b_{y}=b_{r}+b_{m}=b_{r}+b_{\max } \exp \left\{-\left(\beta_{x} \sigma_{x}+\beta_{y} \sigma_{y}\right)\right\}
$$

where $\beta_{x}$ and $\beta_{y}$ are the coefficients related to the fracture closure in y-direction under the normal stresses $\sigma_{x}$ and $\sigma_{y}$, respectively.

Now the effect of shear dilation needs to be considered. Similar equations to Equations $(4 a, b)$ are suggested for the permeability contributions from shear dilations, as follows:

$$
k_{d x}=\frac{f_{d x}}{12} d_{x}^{3}
$$




$$
k_{d y}=\frac{f_{d y}}{12} d_{y}^{3}
$$

where $k_{d x}, k_{d y}$ are the equivalent permeability caused by the shear dilations of fractures; $f_{d x}, f_{d y}$ are the equivalent frequencies of dilating fractures; and $d_{x}, d_{y}$ are the equivalent apertures of dilating fractures in $\mathrm{x}$ - and $\mathrm{y}$-directions, respectively. Since only the near-critically-oriented fractures can dilate, shear dilation occurs only partially, while the other fractures are still without dilation (Figure 11, Figure 13). Because of this significant channeling effect, equivalent frequencies of dilating fractures $\left(f_{d x}, f_{d y}\right)$ will be smaller than the equivalent frequencies $\left(f_{x}, f_{y}\right)$ defined previously (Figure 17). The equivalent aperture of dilating fractures may be formulated according to the following conditions:

For $k<k_{c}, d_{x}=0, d_{y}=0$

For $k \geq k_{c}, d_{x}=d_{\max }\left[1-\exp \left\{-\gamma_{x}\left(k-k_{c}\right)\right\}\right], d_{y}=d_{\max }\left[1-\exp \left\{-\gamma_{y}\left(k-k_{c}\right)\right\}\right]$

where $k_{c}$ is the critical stress ratio that can cause the failure of fractures and $d_{\max }$ is the maximum aperture of fractures after dilation, which can be obtained from laboratory experiments. The values for critical stress ratio and critical orientation of fracture for failure can be calculated from the Coulomb failure criterion as shown below, assuming no cohesion in the fractures [36]:

$$
\begin{aligned}
k_{c} & =\frac{1+\sin \phi}{1-\sin \phi} \\
\phi_{f} & =90-\left(45+\frac{\phi}{2}\right)
\end{aligned}
$$


where, $\phi$ is the friction angle of fractures and $\phi_{f}$ is failure angle of critically oriented fractures, measured from the direction of maximum principal stress.

Final equivalent permeability in $\mathrm{x}$ and $\mathrm{y}$ directions $\left(k_{x}, k_{y}\right)$ can then be calculated by superimposing the contributions from normal closures and shear dilations of fractures:

$$
\begin{aligned}
& k_{x}=k_{n x}+k_{d x}=\frac{f_{x}}{12} b_{x}{ }^{3}+\frac{f_{d x}}{12} d_{x}^{3} \\
& k_{y}=k_{n y}+k_{d y}=\frac{f_{y}}{12} b_{y}{ }^{3}+\frac{f_{d y}}{12} d_{y}{ }^{3}
\end{aligned}
$$

or in more explicit form,

$$
\begin{aligned}
& k_{x}=\frac{f_{x}}{12}\left[b_{r}+b_{\max } \exp \left\{-\left(\alpha_{x} \sigma_{x}+\alpha_{y} \sigma_{y}\right)\right\}\right]^{3}+\frac{f_{d x}}{12}\left[d_{\max }\left[1-\exp \left\{-\gamma_{x}\left(k-k_{c}\right)\right\}\right]\right]^{3} \\
& k_{y}=\frac{f_{y}}{12}\left[b_{r}+b_{\max } \exp \left\{-\left(\beta_{x} \sigma_{x}+\beta_{y} \sigma_{y}\right)\right\}\right]^{3}+\frac{f_{d y}}{12}\left[d_{\max }\left[1-\exp \left\{-\gamma_{y}\left(k-k_{c}\right)\right\}\right]\right]^{3}
\end{aligned}
$$

The dilation terms in Equations (12) and (13) become zero when the stress ratio is below the critical stress ratio.

\subsection{Determination of the Parameters and Comparison with Numerical Experiments}

Figure 18 shows the procedure for determining the parameters related to the suggested empirical equations. Critical stress ratio can be calculated from Equation (10), and the parameters related to the aperture response of a single fracture, such as the residual aperture, maximum closure, and maximum aperture after dilation, can be determined from the laboratory tests. The other parameters should be determined from numerical experiments on realistically generated DFN realizations. As 
shown in the Figure 18, the equivalent frequencies $\left(f_{x}, f_{y}\right)$ can be calculated from the permeability experiments before the application of stresses and coefficients for stresses $\left(\alpha_{x}, \alpha_{y}, \beta_{x}, \beta_{y}\right)$ can be determined through multiple regressions, based on the values obtained before the dilation starts. Lastly, the parameters $\left(f_{d x}, f_{d y}, \gamma_{x}, \gamma_{y}\right)$ related to the dilation can be determined by multiple regressions from the contributions of dilations after shear failure starts to develop. Table 3 shows the results from such a study. Because the fracture pattern in the current study is near-random due to the existence of four fracture sets and their low Fisher constants, the equivalent fracture frequency in $\mathrm{x}$ and $\mathrm{y}$ directions $\left(f_{x}, f_{y}\right)$ are similar. Fracture dilation frequencies $\left(f_{d x}, f_{d y}\right)$ are much smaller than the equivalent fracture frequency owing to stress-induced channeling, since only parts of the fractures dilate. The ratio of fracture frequency with dilation to the total equivalent fracture frequency indicates the extent of channeling when dilation is significant. Higher stress coefficients $\left(\alpha_{x}, \alpha_{y}, \beta_{x}, \beta_{y}\right)$ indicate higher sensitivity to the stress states; note that the equivalent directional permeability in a particular direction, for example in the x-direction, is influenced by both $\mathrm{x}$ - and $\mathrm{y}$ directional stresses with varying degrees of significance and sensitivity.

The constructed models are compared with the numerical experiments in Figure 19. The constructed models match reasonably well with the results of numerical experiments and capture the observed dilation behavior with an acceptable degree of agreement.

\section{Discussion on outstanding issues}

The result of this paper should be interpreted with an awareness of the effect of both geometric input parameters and constitutive model of the fractures. Aperture value plays a major role in the hydraulic behavior of fractured rock masses: the initial aperture for this analysis was $30 \mu \mathrm{m}$ and the residual aperture was $5 \mu \mathrm{m}$. The more-than-two-orders of magnitude in permeability reduction from the increased stresses are constrained by this aperture range corresponding to the cubic of the six 
times decrease of aperture. The change in permeability can be larger with more variations of apertures. On the other hand, the trend of stress-permeability is constrained by the fracture constitutive model for normal closures and normal stresses. The consideration of a non-linear stepwise stiffness model for normal displacement of fracture made it possible to capture the sensitive permeability change at low stress levels. Care should also be taken in interpreting the effect of shear dilation. The maximum possible aperture by dilation was $50 \mu \mathrm{m}$ in this study, and the influence on equivalent permeability from shear dilation is a function of this limit of apertures. We anticipate that the influence of shear dilation will be far larger when larger apertures and longer fractures are used.

Our approach is able to account for changes in permeability caused by the combined mechanisms of normal closure and shear dilation. An approach dependent on only one of these mechanisms is not enough to explain the change of permeability induced by stress. In general, permeability can increase or decrease with stress increase depending on the state of stresses rather than a single component or an averaged value of stresses. Hence, changes in permeability should be investigated in the context of changes in stress tensor. These mechanisms have to be explained in relation to both stress conditions and fracture geometries. It is recommended that detailed numerical mechanical and hydraulic analysis should be done, based on realistic and site-specific DFN realizations for practical problems.

Fractures that intersect the boundary of the model tend to be more vulnerable to shear displacement because of no constraints from the intersected boundary. To investigate the possible effect of this boundary effect, we generated a larger DFN model $(10 \mathrm{~m} \times 10 \mathrm{~m})$ and applied the same boundary stress conditions. Figure 20 shows the comparison between the fracture aperture distributions of the larger model and the small (but still representative) model taken from the same fracture network 
used in this paper. Aperture distributions of both models are generally identical, except for a few regions (at the corners). At the corners of the smaller model (top left, bottom left, and bottom right), much larger fracture apertures can be found, since fractures intersected by the two corners of the model could slide more easily with larger dilations compared to the same, but constrained, fractures in the larger model. However, since numerical experiments for the permeability were conducted with the two side boundaries set as impermeable, overestimated apertures at the corners actually do not affect the results with any significance. Hence, the boundary effect does not seem to be significant in this study.

As often observed in the field, only a few fractures or clusters of fractures dominate the fluid flow in fractured hard rocks. This phenomenon is numerically reproduced qualitatively (in general) and quantitatively for this study. As expected, shear dilation of near-critically-oriented fractures is the main reason for this flow localization. The critical stress state for the onset of shear failure and subsequent shear dilation predicted using Equation (10) matched reasonably well with numerical experiments. However, careful observation of dilated fractures and flow pattern shows that numerical analysis is necessary to identify the dilated fractures and quantify their effect. It was confirmed that critically oriented fractures were more vulnerable to dilation. It was also found that the longer fractures could dilate more, and that fractures need to be connected to neighboring fractures of similar orientation for shear displacement to produce channeling of flow paths.

It is worthwhile to investigate whether the observed stress-dependent permeability is reversible. Since there have been no such experiments at large scales, this can only be inferred from the laboratory experiments on single fractures. Upon unloading, normal closure/opening will be only partially reversible due to the asperity damage of fractures. Therefore, permeability can partially increase back with the decrease of the stresses when the stress ratio is not large enough to cause 
failure. However, when permeability change is induced by shear dilation, an irreversible (permanent) increase of permeability could be observed. This irreversible increase in permeability is caused by shear dilation during inelastic (and irreversible) shear deformation of critically-stressed fractures, which will not recover back to the initial state upon unloading. Therefore, if the test block is unloaded, the equivalent permeability will show an irreversible increase and there will be remaining flow channeling along previously sheared fractures. A comprehensive analysis of the entire loading, shearing and unloading path is yet to be conducted and would require a proper fracture constitutive model for mechanical unloading.

Two-dimensional analysis of this paper is effective for the conceptual understanding of hydromechanical behavior of fractured rock masses. However, in site-specific study, the limitation of two-dimensional analysis should be considered. In two-dimensional analysis, the orientation of fractures (apparent dip) is dependent on the orientation of reference plane used for the analysis and the connectivity in two-dimensional model can be different depending on the location of reference plane cut in the three-dimensional model. Further, the fractures are modeled to have strikes only normal to the model plane in two-dimensional model. Therefore, two-dimensional modeling is limited and three-dimensional modeling is necessary for a true representation of fracture geometry and subsequent hydromechanical behavior. It is not straighforward to estimate the extent of error involved in two-dimensional analysis without actual comparison of two- and three-dimensional analysis and further research is needed on this aspect. Two reasons can be pointed out for the difficulty of three-dimensional modeling: (1) insufficient fracture constitutive models existing today that can consider the anisotropic transmissivity in dilated fracture planes, and (2) the extreme computing load for three-dimensional modeling. Even though three dimensional fracture models exist for mainly mechanical behavior, such as in [37], there is a need for further research for including the coupled hydro-mechanical processes in the three dimensional models. An 
experimental and numerical study suggests more permeable flow in the direction perpendicular to the shear displacement than in the direction parallel to it $[38,39]$. However, a different result has also been reported, arguing (using analytical approximations) that the degree of anisotropy is more or less negligible compared with the remarkable increase caused by shear dilation [40]. A study reported 'estimated' flow perpendicular to the two-dimensional model plane (expressed as third dimension) depending on the shape of openings [21]. It observed the localized flow in direction perpendicular to two-dimensional model through the 'pipes' caused by the openings of some fracture intersections, however, actual numerical calculation in three dimensions could not be conducted. Furthermore, three-dimensional modeling of both hydraulic and mechanical behavior with the explicit representation of fractures is computationally intensive [16, 41].

However, the three-dimensional modeling will be feasible in the near future with ever increasing of today's computing capacity [42] and is needed because of the general three-dimensional nature of fracture orientations.

Another limitation of the approach in this paper is the neglect of correlations between the fracture length (size) and aperture in initial model, as reported in [30]. The reason for excluding this effect are two: 1) larger fractures can always be represented as deterministic features in numerical models instead of being contributing factors to behavior of REV that basically consider contributions from more stochastic fracture populations; 2) lack of definite fracture length and aperture relation at the background site for the current study. However, this is an important issue since it affects different REV sizes and properties at different scales and may have significant impacts on practical applications.

The suggested empirical equations of stress-dependent permeability in this paper require a series of numerical experiments to determine the associated parameters, because in situ physical tests with 
large numbers of fractures are not practical. So far, it looks promising that these empirical equations may be able to describe behavior of fractured rock masses (in which case they could be used in large-scale coupled hydromechanical models) under certain conditions. However, further work needs to be done to establish their validity for stochastic DFN models and improve its capacity for more general stress-paths so that it can serve as an important part of more comprehensive constitutive models for coupled hydro-mechanical processes of fractured rocks.

\section{Summary and Conclusions}

In this paper, the stress-dependent permeability of fractured rock masses is investigated through numerical experiments considering nonlinear normal deformation and shear dilation of fractures, using the distinct element method program, UDEC, based on a realistic realization of discrete fracture network (DFN) geometry. A set of empirical stress-permeability equations is suggested based on the proposed approach and results. The necessary conditions for performing numerical investigations are put forward in this paper: the available initial REV of the model (both mechanical and hydraulic), the non-linear normal stress-closure behavior of the fractures, and the representation of the effects of fracture roughness on aperture during shear dilation with a non-zero dilation angle. This study presents a systematic research on the stress-dependent permeability based on the above conditions at a fundamental level, rather than a site-specific application.

Main conclusions are summarized as follows.

Equivalent permeability decreases with increase in stresses, when the differential stress is not large enough to cause shear dilations of fractures. In this case, normal closure of fractures is the dominating mechanism for characterizing stress-dependent permeability. The reduction of permeability was more than two orders of magnitude, under the stress increase up to $40 \mathrm{MPa}$ (from 
zero stress) in this study. The more sensitive permeability change at lower stress levels was captured due to the hyperbolic behavior of the normal stress-normal closure of rock fracture model.

The equivalent permeability increases with the increase in differential stresses, when the stress ratio was large enough to cause continued shear dilation of fractures. In this case, shear dilation is the dominating mechanism in characterizing the stress-dependent permeability. The maximum contribution of dilation is more than one order of magnitude in permeability in this study. The increase of permeability stabilizes when shear dilation reaches its stationary value. The critical stress that indicates the onset of fracture failure could be estimated well with analytical solutions considering only fracture friction angle. However, the exact locations and extents of shear dilations of fractures can only be identified through numerical experiments.

Channeling effects of fluid flow in fractures induced by stress changes were found from the numerical modeling. The results show that fluid flow becomes uneven and clustered as a result of localized shear dilations of fractures, and a major portion of the flow may be carried by only a few connected fractures. The results from this paper confirm that high differential stresses, causing fracture shear failure at certain orientations, is one of the major reasons for highly channeled flow. The numerical analysis in this paper suggests that the lengths of fractures and their connectivity are also important factors in determining these major fluid-carrying features. It is the first time that such a clear demonstration of stress-induced flow channeling by numerical modeling in fractured rocks was reported, using a DEM approach.

Increase in permeability anisotropy begins to be important with the increase of differential stresses. This anisotropy can be more prominent with the onset of stress-induced shear dilation of fractures. For the problem studied in this paper, the permeability in the horizontal direction was eight times 
larger than that in the vertical direction when the stress ratio was five, due to the highly mobilized shear dilation, even though the permeability was isotropic before the stress change was imposed.

A set of empirical equations that account for both normal closure and shear dilation is suggested for modeling the stress-dependent permeability. In addition to the parameters determined from the laboratory, a few other parameters need to be obtained from numerical experiments, as conducted in this study. Predicted permeability from the suggested equations provides reasonable agreement with the results obtained from numerical experiments. Further work is under way to improve the validity of this empirical equation and its applicability to large-scale modeling.

\section{ACKNOWLEDGMENTS}

The financial support by the European Commission through the BENCHPAR project (FIKWCT-2000-00066) and the Swedish Nuclear Inspectorate (SKI) through the DECOVALEX III project are greatly acknowledged. The authors would like to extend sincere gratitude to the colleagues in the DECOVALEX III and BENCHPAR projects for their comments on this work during the course of several Workshops. Special thanks are given to Ove Stephansson, John Hudson, Johan Andersson, Leslie Knight, Philipp Blum, Johan Öhman, Auli Niemi and Rae Mackay for fruitful discussions and helpful comments. The second and third authors would like to acknowledge the support of Office of Basic Energy Sciences, Geoscience Program, of the United States Department of Energy under Contract Number DE-AC03-76SF00098.

\section{REFERENCES}

[1] Rutqvist J, Stephansson O, The role of hydromechanical coupling in fractured rock engineering, Hydrogeology Journal 2003;11:7-40 
[2] Makurat A, Barton N, Rad NS, Bandis S, Joint conductivity variation due to normal and shear deformation, In: Barton N. \& Stephansson O (eds) Proc. Int. Symp. Rock Joints, Balkema, Rotterdam, 1990:535-540

[3] Olsson R, Barton N, An improved model for hydromechanical coupling during shearing of rock joints, Int J Rock Mech Min Sci 2001;38(3):317-29

[4] Barton CA, Zoback MD, Moos D, Fluid flow along potentially active faults in crystalline rock, Geology 1995;23(8):683-6

[5] Ito T, Hayashi K, Role of stress-controlled flow pathways in HDR geothermal reservoirs, Pure appl geophys 2003;160:1103-24

[6] Pusch R, Alteration of the hydraulic conductivity of rock by tunnel excavation, Int $J$ Rock Mech Min Sci \& Geomech Abstr 1989;26(1):79-83

[7] Kelsall PC, Case JB, Chabannes CR, Evaluation of excavation-induced changes in rock permeability, Int J Rock Mech Min Sci \& Geomech Abstr 1984;21(3):123-35

[8] Daemen JJK, Slip zones for discontinuities parallel to circular tunnels or shafts, Int J Rock Mech Min Sci \& Geomech Abstr, 1983;20(3):135-48.

[9] Shen B, Barton N, The disturbed zone around tunnels in jointed rock masses, Int. J. Rock Mech. Min. Sci. 1997;34(1):117-25

[10] Bäckblom G, Martin CD, Recent experiments in hard rocks to study the excavation response: Implications for the performance of a nuclear waste geological repository, Tunnelling and Underground Space Technology 1999;14(3):377-94

[11] Bai M, Elsworth D, Modeling of subsidence and stress-dependent hydraulic conductivity for intact and fractured porous media, Rock Mech Rock Engng 1994;27(4):209-34

[12] Chen M, Bai M, Modeling stress-dependent permeability for anisotropic fractured porous rocks, Int J Rock Mech Min Sci, 1998;35(8):1113-9 
[13] Bai M, Meng F, Elsworth D, Roegiers JC, Analysis of stress-dependent permeability in nonorthogonal flow and deformation fields, Rock Mech Rock Engng 1999;32(3):195-219

[14] Oda M, An equivalent continuum model for coupled stress and fluid flow analysis in jointed rock masses, Water Resour Res 1986;22(13):1845-56

[15] Monsen K, Makurat A, Barton N, Numerical modeling of disturbed zone phenomena at Stripa, In: Hudson JA (ed), ISRM Symp, EUROCK 92 - Rock Characterization, 1992:354-9.

[16] Damjanac B, Fairhurst C, Brandshaug T, Numerical simulation of the effects of heating on the permeability of a jointed rock mass, Proc 9th ISRM Congress, Paris, 1999:881-5

[17] Itasca Consulting Group, UDEC user's guide, Ver. 3.1, Minnesota, 2000.

[18] Zhang X, Sanderson DJ, Numerical Modelling and Analysis of Fluid Flow and Deformation of Fractured Rock Masses, Pergamon, Oxford, 2002, 288p

[19] Zhang X., Sanderson D. J., Harkness R. M., Last N. C., Evaluation of the 2-D permeability tensor for Fractured Rock masses, Int J Rock Mech Min Sci \& Geomech Abstr 1996;33(1):1737

[20] Zhang X, Sanderson DJ, Effects of stress on the 2-D permeability tensor of natural fracture networks, Geophys J Int 1996;125:912-24

[21] Zhang X, Sanderson DJ, Effects of loading direction on localized flow in fractured rocks, In: Yuan JX (ed), Computer Methods and Advances in Geomechanics, Balkema, Rotterdam, 1997:1027-32

[22] Min KB, Jing L, Numerical determination of the equivalent elastic compliance tensor for fractured rock masses using the distinct element method, Int $J$ Rock Mech Min Sci 2003;40(6):795-816

[23] Min KB, Jing L, Stephansson O, Determining the Equivalent Permeability Tensor for Fractured Rock Masses Using a Stochastic REV Approach: Method and Application to the Field Data from Sellafield, UK, Hydrogeology Journal (in press) 
[24] Barton, N. Modelling rock joint behaviour from in situ block tests: implications for nuclear waste repository design. Office of Nuclear isolation, Columbus, OH, ONWI-308, 1982:96pp

[25] Bandis SC, Lumsden AC, Barton NR, Fundamentals of rock joint deformation, Int. J. Rock Mech. Min. Sci. \& Geomech. Abstr. 1983;20(6):249-68

[26] Bawden WF, Curran JH, Roegiers J-C, Influence of Fracture Deformation on Secondary Permeability - A Numerical Approach, Int. J. Rock Mech. Min. Sci \& Geomech Abstr 1980;17(5):265-79

[27] Anderson J, Knight L, DECOVALEXIII Project, TASK 3, BMT2 protocol, Understanding the Impact of Upscaling THM processes on Performance Assessment, version 6.0, Stockholm, 2000 (unpublished report)

[28] Min KB, Rutqvist J, Tsang CF, Jing L, A block-scale stress-permeability relationship of fractured rock determined by numerical experiments, In: Stephansson O, Hudson JA, Jing L (eds) Int Conf on Coupled T-H-M-C Processes in Geosystems: GeoProc 2003, Stockholm, 2003:257-62

[29] Wei ZQ, Egger P, Descoeudres F, Permeability Predictions for Jointed Rock Masses, Int J Rock Mech Min Sci \& Geomech Abstr, 1995;32(3):251-61

[30] Ito T, Swenson D, Hayashi K, Effect of thermal deformation on fracture permeability in stressed rock masses, In: Stephansson O, Hudson JA, Jing L (eds) Int Conf on Coupled T-H-MC Processes in Geosystems: GeoProc 2003, Stockholm, 2003:671-76.

[31] Renshaw CE, Park JC, Effect of mechanical interactions on the scaling of fracture length and aperture,. Nature 1997;386:482-4.

[32] Lee CI, Chang KM, Analysis of permeability change and groundwater flow around underground oil storage cavern in Korea, Proc 8th ISRM Congress, Tokyo, Balkema, Rotterdam, 1995:779-782 
[33] Tsang CF, Neretnieks I, Flow Channeling in heterogeneous Fractured Rocks, Reviews of Geopysics 1998;36(2):275-98

[34] Snow DT, Anisotropic Permeability of Fractured Media, Water Resour Res 1969;5(6):1273-89

[35] Rutqvist J, Tsang CF., Tsang Y., Analysis of stress-and moisture-induced changes in fractured rock permeability at the Yucca mountain drift scale test, In: Stephansson O, Hudson JA, Jing L (eds) Int Conf on Coupled T-H-M-C Processes in Geosystems: GeoProc 2003, Stockholm, 2003:147-52.

[36] Brady BHG, Brown ET, Rock Mechanics for underground mining, 2nd ed, Chapman \& Hall, London, 1993, 571p.

[37] Jing L, Numerical modellinig of jointed rock masses by distinct element method for two- and three-dimensional problems, PhD thesis, Luleå University of Technology, Sweden, 1990

[38] Yeo IW, De Freitas MH, Zimmerman RW, Effect of shear displacement on the aperture and permeability of a rock fracture, Int J Rock Mech Min Sci 1998;35(8):1051-70

[39] Koyama T, Fardin N, Jing L, Shear induced anisotropy and heterogeneity of fluid flow in a single rock fracture with translational and rotary shear displacements - a numerical study, Int $J$ Rock Mech Min Sci 2004;41(3):426 (Paper No.2A08)

[40] Kim HM, Inoue J, Analytical approach for anisotropic permeability through a single rough rock joint under shear deformation, J Geophys Res 2003;108(B8):2366

[41] Thoraval AT, Renaud V. Hydro-mechanical upscaling of a fractured rockmass using a 3D numerical approach, In: Stephansson O, Hudson JA, Jing L (eds) Int Conf on Coupled T-H-MC Processes in Geosystems: GeoProc 2003, Stockholm, 2003:263-68

[42] Cundall PA, A Discontinuous Future for Numerical Modelling in Geomechanics?, Geotech. Eng.,2000;149(1):41-7. 
Table 1. Fracture parameters used for DFN generation [27]

\begin{tabular}{lllll}
\hline Set & $\begin{array}{l}\text { Dip/Dip } \\
\text { direction }\end{array}$ & $\begin{array}{l}\text { Fisher } \\
\text { constant } \\
(\mathrm{K})\end{array}$ & $\begin{array}{l}\text { Fracture } \\
\text { density* } \\
\left(\mathrm{m}^{-2}\right)\end{array}$ & $\begin{array}{l}\text { Mean trace } \\
\text { length* } \\
(\mathrm{m})\end{array}$ \\
\hline 1 & $8 / 145$ & 5.9 & 4.6 & 0.92 \\
2 & $88 / 148$ & 9.0 & 4.6 & 0.92 \\
3 & $76 / 21$ & 10.0 & 4.6 & 0.92 \\
4 & $69 / 87$ & 10.0 & 4.6 & 0.92 \\
\hline
\end{tabular}

* Fracture density and mean trace length are calculated from equation (1) with minimum and maximum cut-off trace lengths. 
Table 2. Model parameters [27]

\begin{tabular}{llc}
\hline & Properties & \\
\hline Intact rock & Elastic modulus $(\mathrm{GPa})$ & 84.6 \\
& Poisson's ratio & 0.24 \\
\hline Fractures & Normal stiffness $(\mathrm{GPa} / \mathrm{m})$ & 434 \\
& Shear stiffness $(\mathrm{GPa} / \mathrm{m})$ & 434 \\
& Friction angle $\left(^{\circ}\right)$ & 24.9 \\
& Dilation angle $\left({ }^{\circ}\right)$ & 5 \\
& Cohesion $(\mathrm{MPa})$ & 0 \\
& Critical shear displacement & 3 \\
& for dilation, $\mathrm{U}_{\mathrm{cs}}(\mathrm{mm})$ & \\
& Initial aperture $(\mu \mathrm{m})$ & 30 \\
& Residual aperture $(\mu \mathrm{m})$ & 5 \\
& Maximum aperture $(\mu \mathrm{m})$ & 50 \\
\hline
\end{tabular}


Table 3. Parameters determined from numerical experiments

\begin{tabular}{lll}
\hline Parameters & Values & \\
\hline Equivalent frequency $\left(f_{x}\right)$ & $4.44(1 / \mathrm{m})$ & \\
Equivalent frequency $\left(f_{y}\right)$ & $5.11(1 / \mathrm{m})$ & \\
Stress coefficient $\left(\alpha_{x}, \alpha_{y}\right)$ for $b_{x}$ & $0.034,0.146$ & \\
Stress coefficient $\left(\beta_{x}, \beta_{y}\right)$ for $b_{y}$ & $0.101,0.071$ & \\
Equivalent dilation frequency $\left(f_{d x}, f_{d y}\right)$ & $0.384,0.046(1 / \mathrm{m})$ & \\
Stress coefficient $\left(\gamma_{x}\right.$ and $\left.\gamma_{y}\right)$ for dilation $d_{x}$ and $d_{y}$ & $1.88,1.95$ & \\
Residual aperture $\left(b_{r}\right)$ & $5(\mu \mathrm{m})$ & Determined at Lab \\
Maximum deformable mechanical aperture $\left(b_{\max }\right)$ & $25(\mu \mathrm{m})$ & Determined at Lab \\
Maximum dilation $\left(d_{\max }\right)$ & $50(\mu \mathrm{m})$ & Determined at Lab \\
Friction angle & $24.9\left({ }^{\circ}\right)$ & Determined at Lab \\
Critical stress ratio $\left(k_{c}\right)$ & 2.45 & Determined from Eq $(10)$ \\
\hline
\end{tabular}




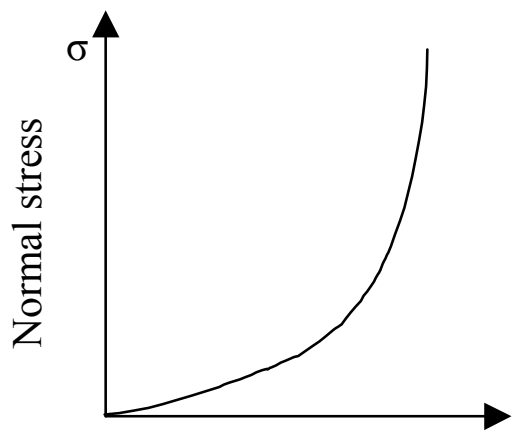

Normal displacement $\delta_{\mathrm{n}}$

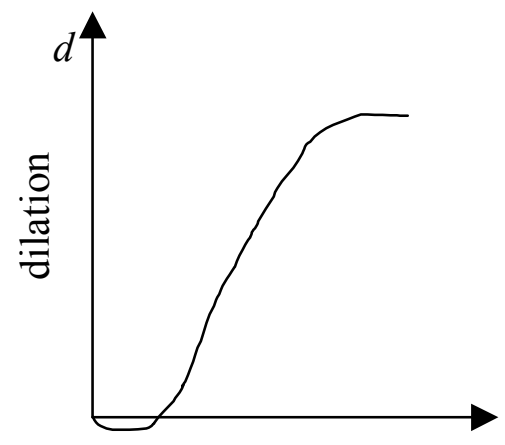

Shear displacement $\delta_{\mathrm{s}}$

b)
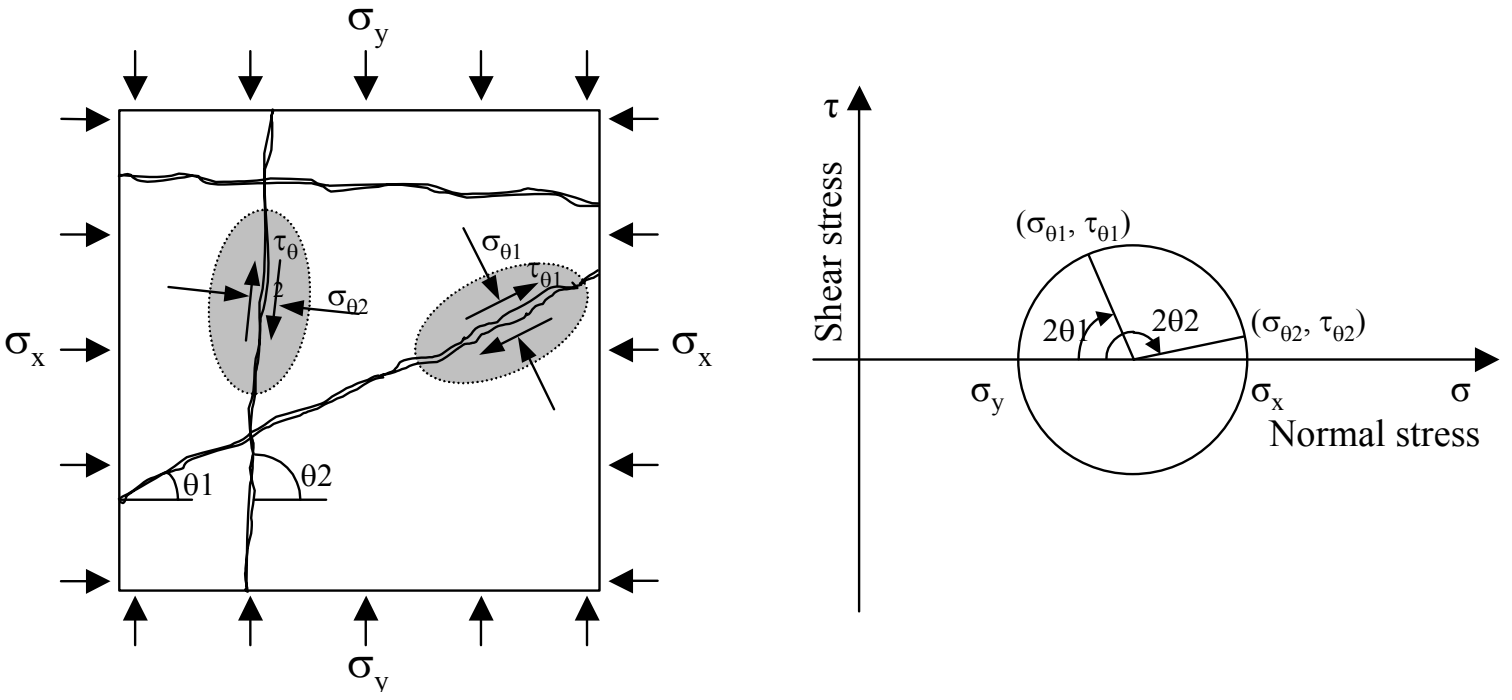

c)

d)

Figure 1. Aperture changes due to two basic fracture deformations and state of stress in fractures. (a) normal stress-displacement relation, (b) shear dilation with respect to shear displacement, (c) stresses in fractures, (d) Mohr Circle (angles are measured from the horizontal line). 


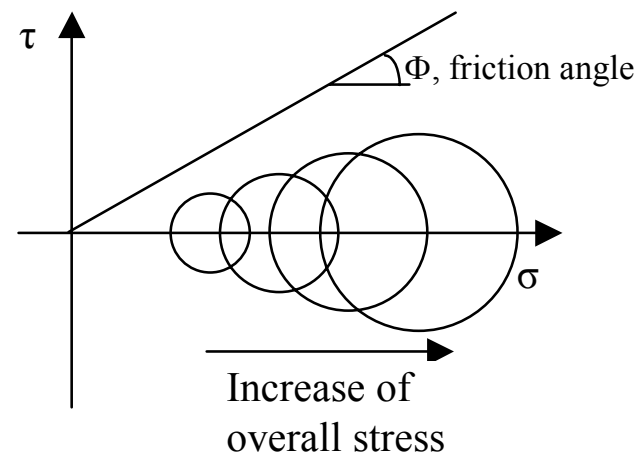

(a)

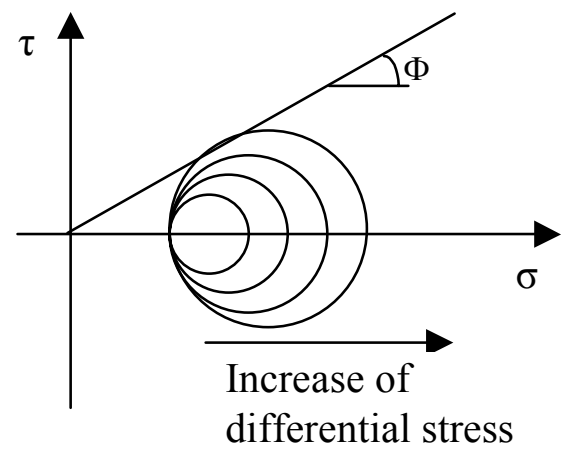

(b)

Figure 2. Two kinds of stress increase used in this study. (a) Increase of stress magnitudes while keeping the stress ratio of horizontal to vertical stress constant. (b) Increase of differential stresses while keeping the vertical, i.e. the lowest stress component, stress constant. The Mohr-Coulomb failure criterion is used with the zero cohesion. 


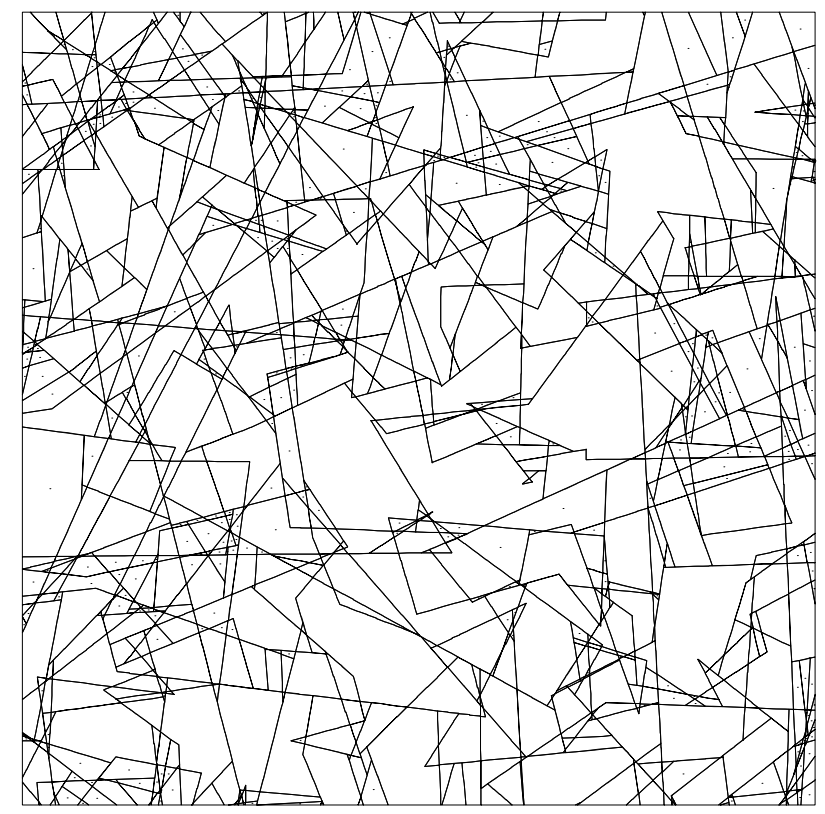

Figure 3. Geometry of fracture system in the DFN model [28] 


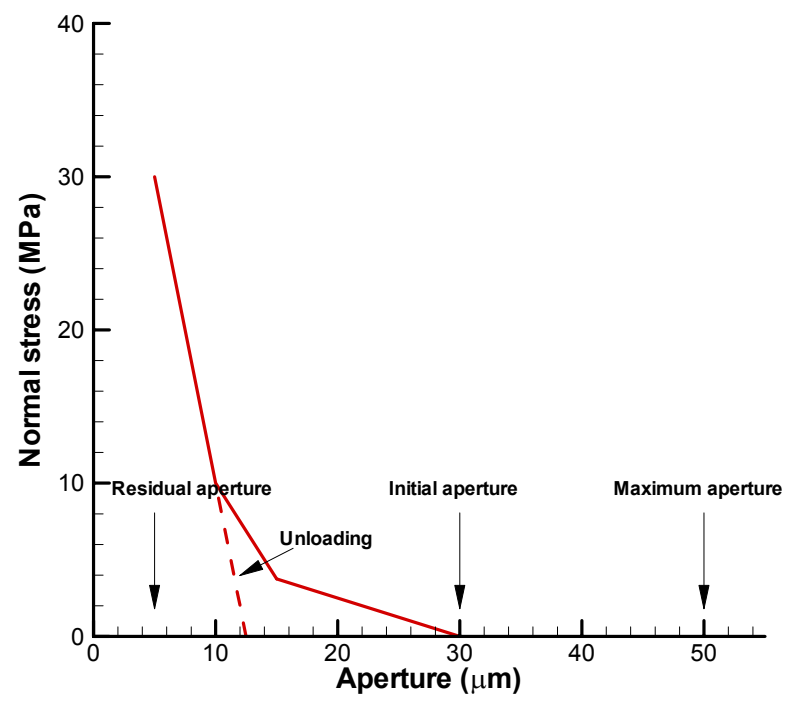

Figure 4. The stepwise nonlinear behavior of fractures under normal stress 


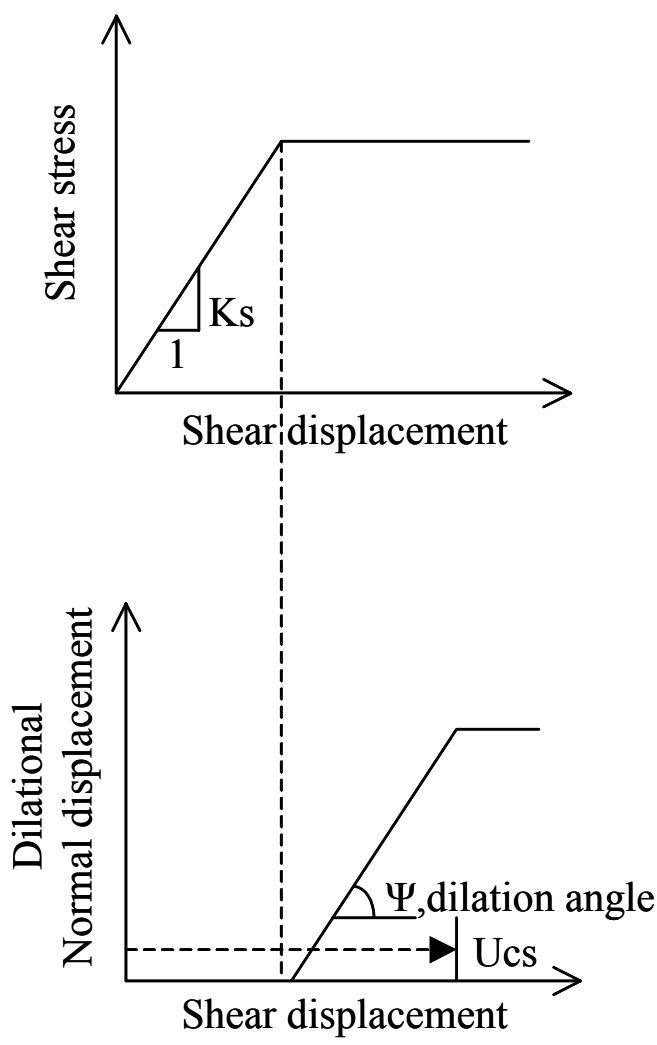

Figure 5. Shear and dilational behavior of fracture (adapted from [17]). Shear stress-displacement relation (above, fracture shear stiffness is expressed as Ks) and shear dilation-displacement relation (below). 


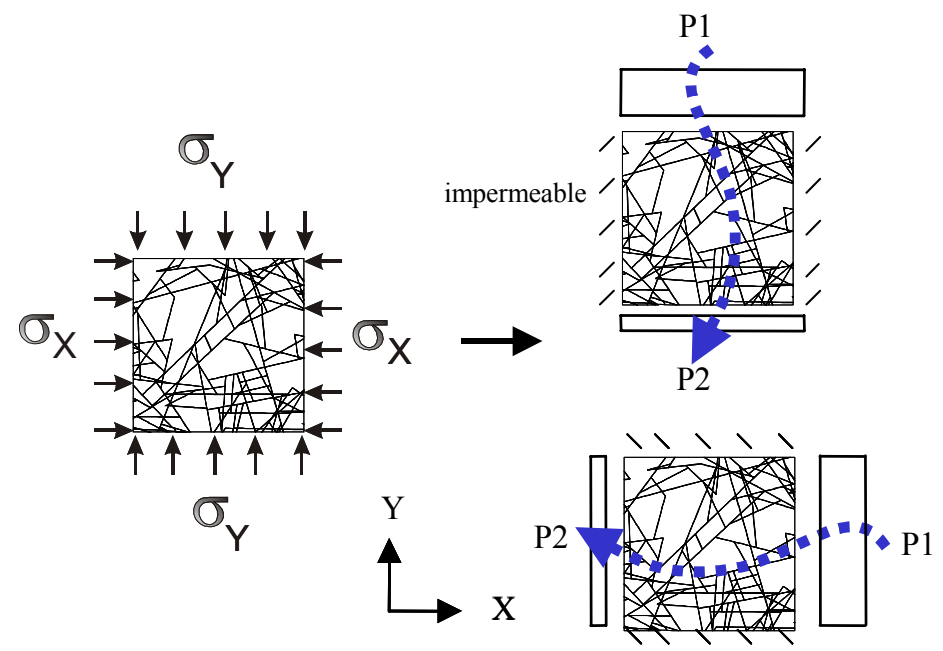

Figure 6. Applications of stress boundary conditions and calculation of equivalent permeability in the $\mathrm{x}$ - and $\mathrm{y}$ - directions [28]. $\sigma_{x}$ and $\sigma_{y}$ indicate the boundary stresses applied in horizontal and vertical directions, respectively. P1 and P2 indicate the hydraulic pressure applied in the boundaries with P1 larger than P2. 

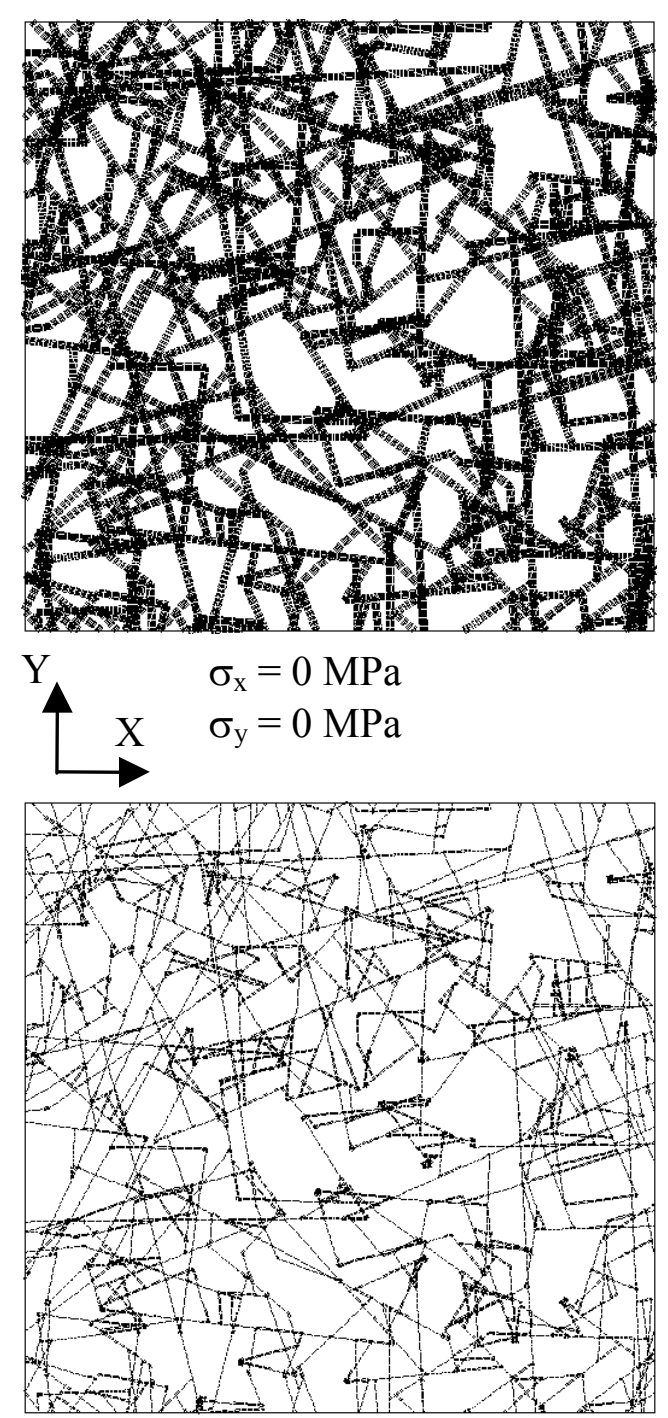

$\sigma_{\mathrm{x}}=13 \mathrm{MPa}$

$\sigma_{\mathrm{y}}=10 \mathrm{MPa}$

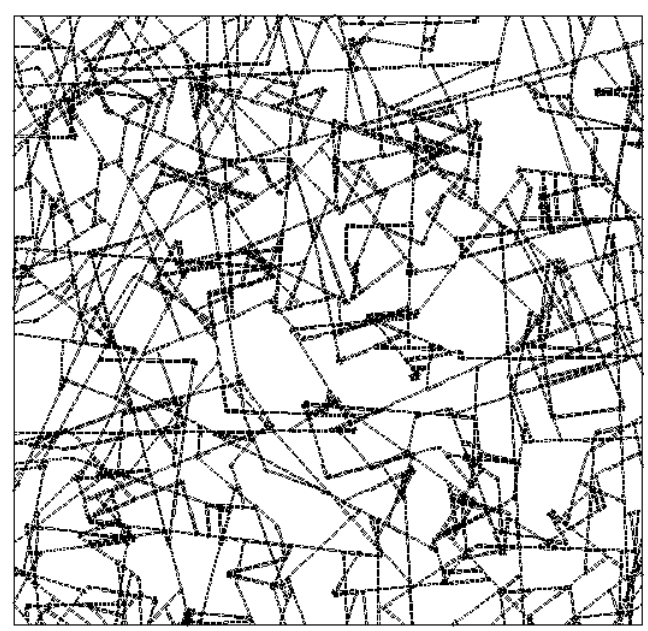

$$
\begin{aligned}
& \sigma_{\mathrm{x}}=5.2 \mathrm{MPa} \\
& \sigma_{\mathrm{y}}=4 \mathrm{MPa}
\end{aligned}
$$

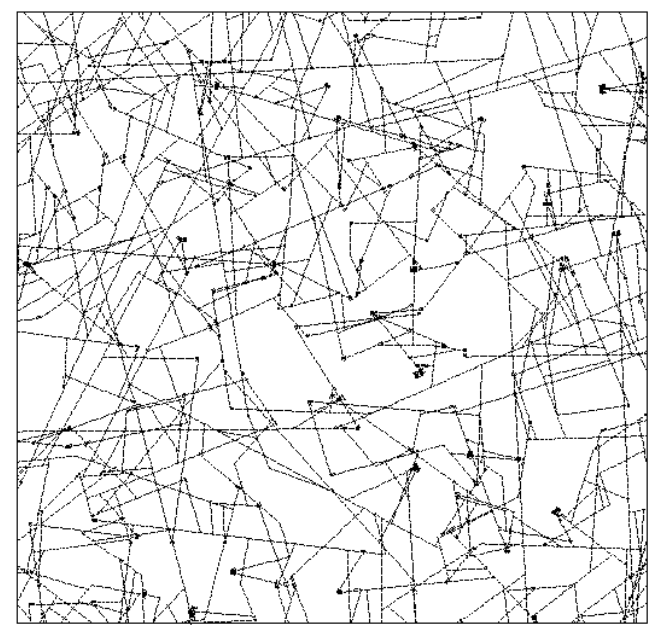

$$
\begin{aligned}
& \sigma_{\mathrm{x}}=26 \mathrm{MPa} \\
& \sigma_{\mathrm{y}}=20 \mathrm{MPa}
\end{aligned}
$$

$\begin{array}{lllllllllll}5 & 10 & 15 & 20 & 25 & 30 & 35 & 40 & 45 & 50 & (\mu \mathrm{m})\end{array}$

Figure 7. Change of fracture apertures with the increase of stresses for the fixed $\mathrm{k}$ ratio of 1.3. The thickness of lines indicates the magnitude of apertures. Mean apertures of four cases were 30, 16.8, 11.9 and $8.8 \mu \mathrm{m}$, respectively. 


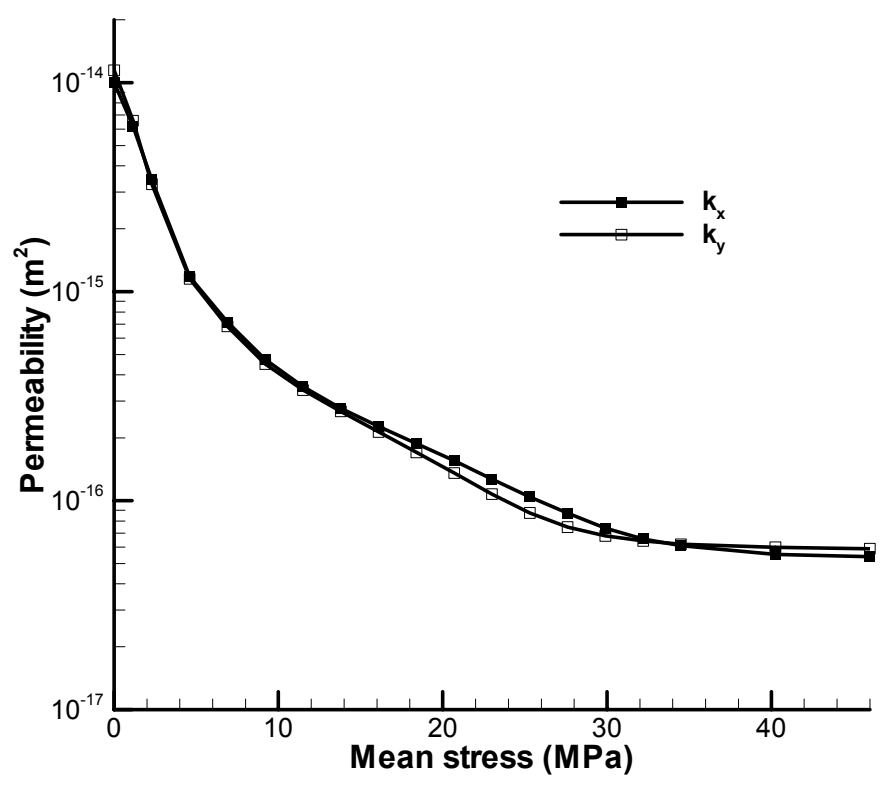

Figure 8. Permeability ( $k_{x}$ and $k_{y}$ ) change versus stress change with the fixed ratio of horizontal to vertical stresses $=1.3$. Stress is expressed as mean of horizontal and vertical stresses. 


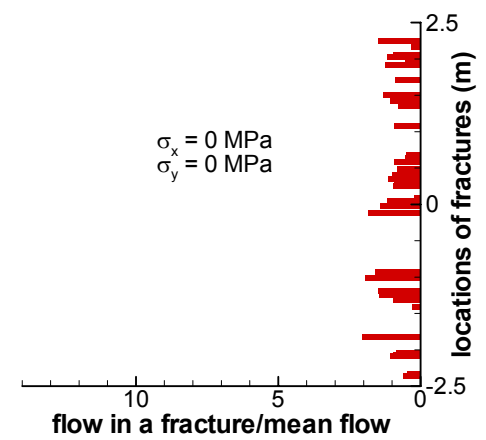

(a)

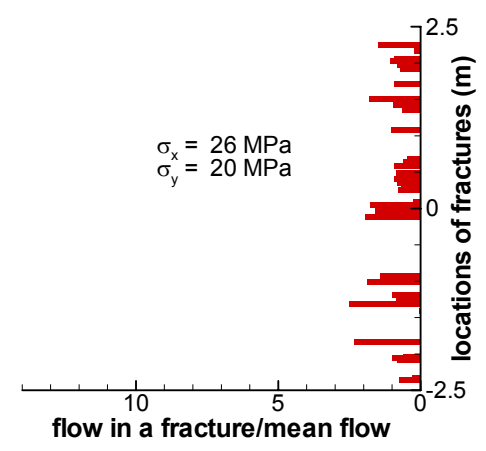

(d)

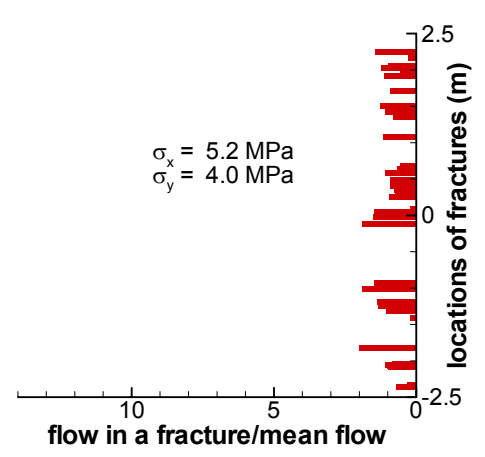

(b)

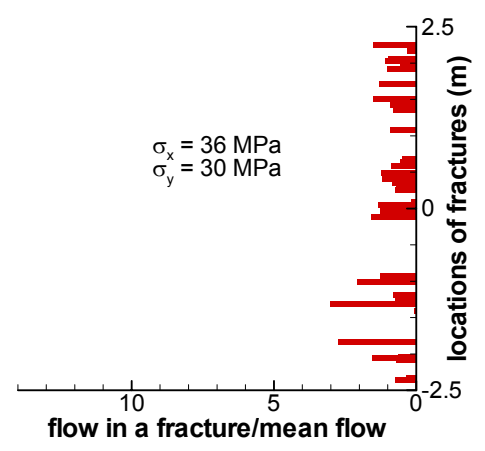

(e)

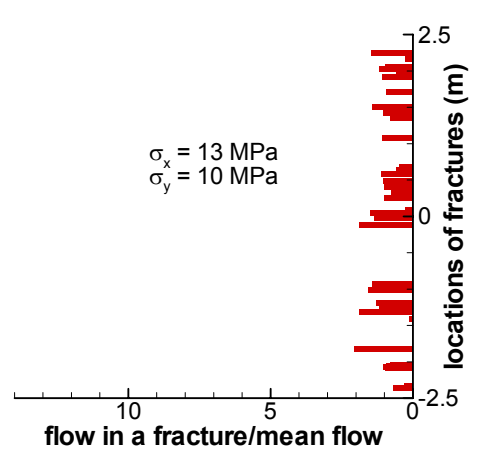

(c)

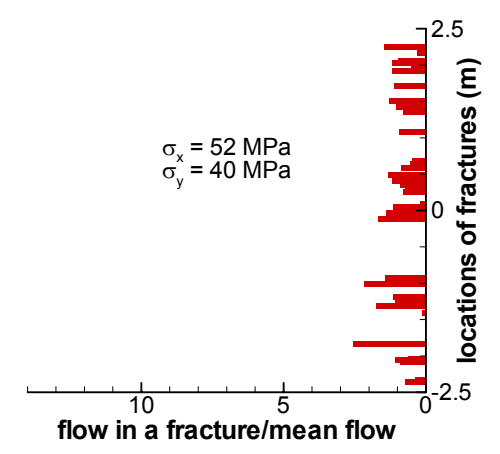

(f)

Figure 9. Normalized flow rates in each fracture intersecting the left vertical boundary of the model. Flow rates are normalized with respect to the mean flow rates (total flow rate divided by the number of fractures) in the boundary. For instance, normalized flow rate 1 represents completely even flow in each fracture along the boundary. The total number of fractures intersecting the left vertical boundary is forty. (a) to (f) show the normalized flow rates in each stress step with fixed stress ratio, $\mathrm{k}$. 

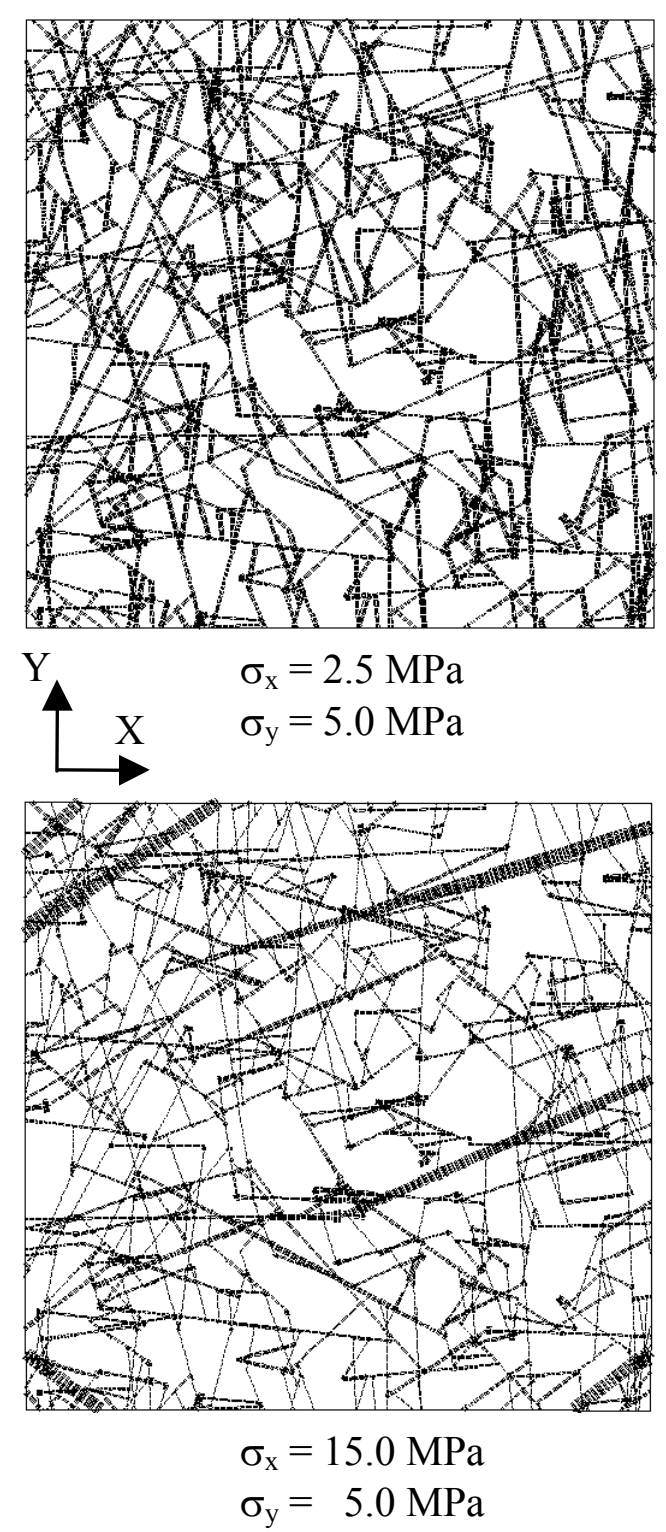

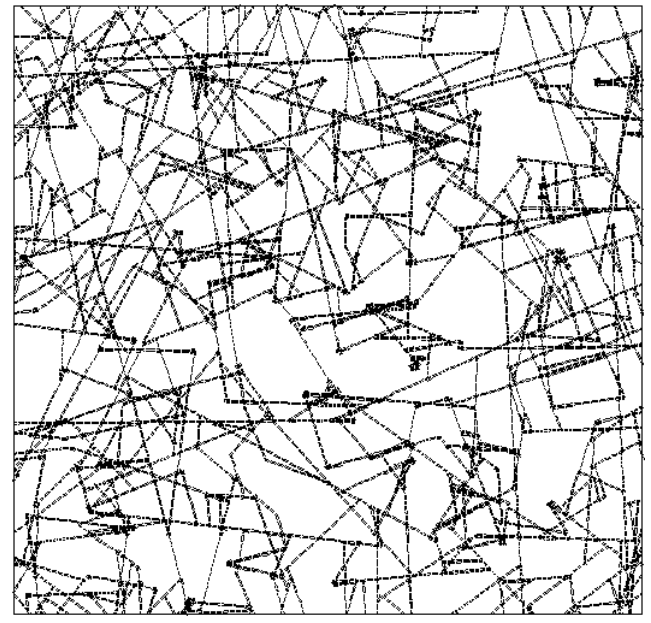

$$
\begin{aligned}
& \sigma_{\mathrm{x}}=10.0 \mathrm{MPa} \\
& \sigma_{\mathrm{y}}=5.0 \mathrm{MPa}
\end{aligned}
$$

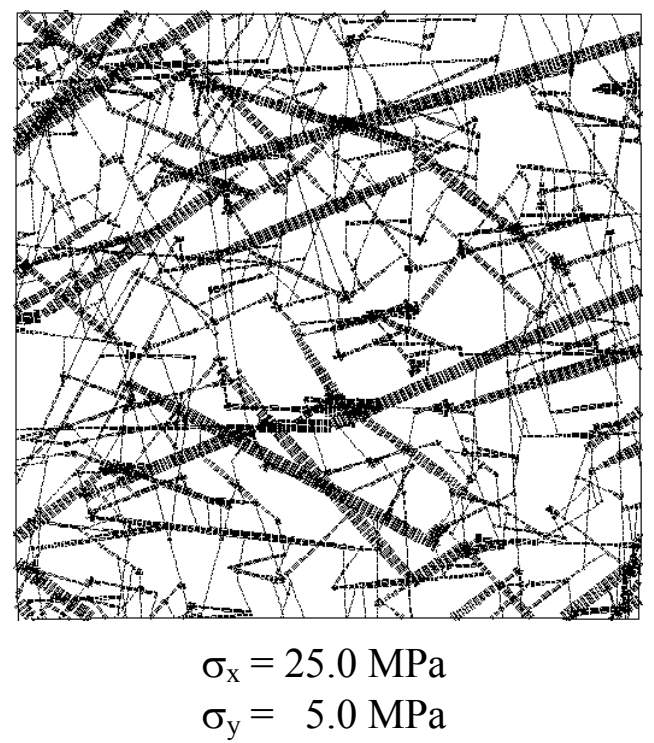

$5 \quad 1015202530 \quad 3540 \quad 4550 \quad(\mu \mathrm{m})$

Figure 10. Changes in fracture apertures with the increase of differential stresses with the fixed vertical stress $=5 \mathrm{MPa}$. The thickness of the line indicates the magnitude of apertures. 


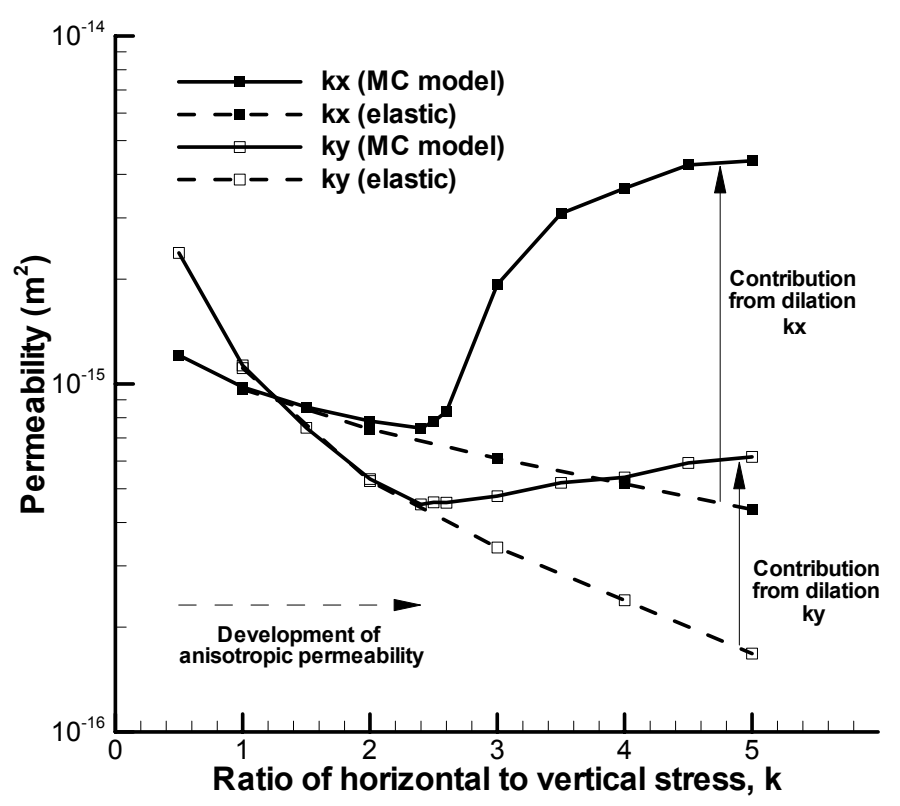

Figure 11. Equivalent permeability $\left(k_{x}\right.$ and $\left.k_{y}\right)$ change due to the change in stress ratio. Differential stress is increased while keeping the magnitude of vertical stress constant. Mohr Coulomb (MC) model (solid lines) is compared with the pure elastic model with no shear failure (dashed lines). 


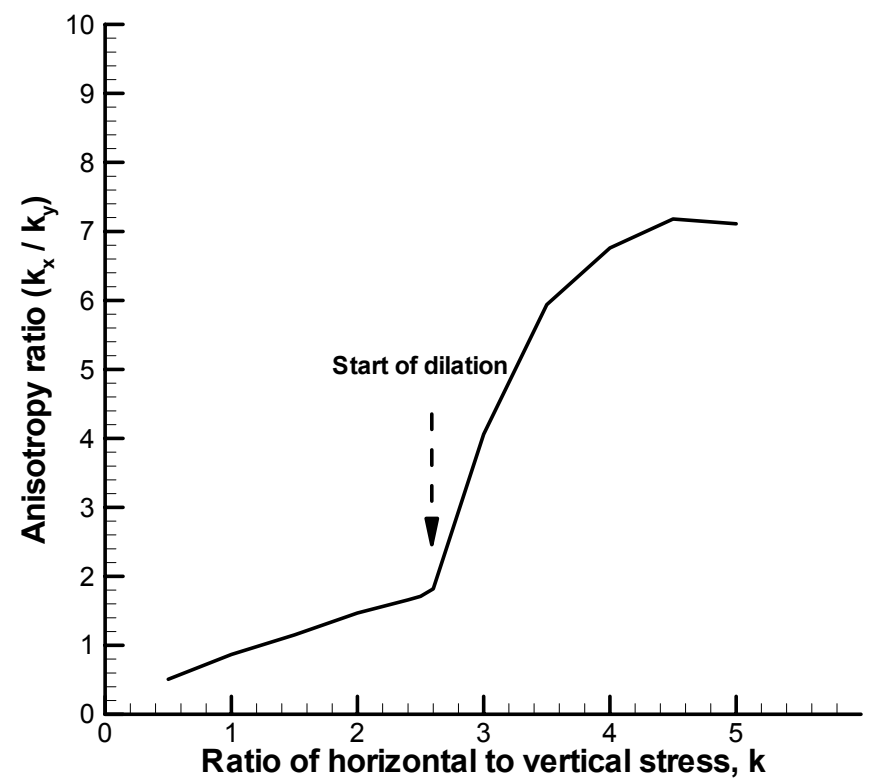

Figure 12. Anisotropy ratio $\left(k_{x} / k_{y}\right)$ of the equivalent permeability with the increase of horizontal to vertical stress ratio. 

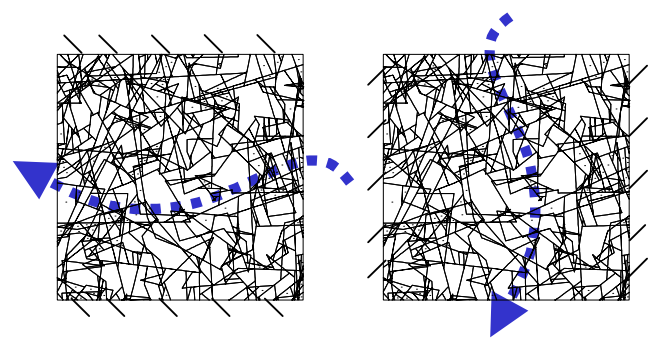

\section{Direction \\ of Flow}
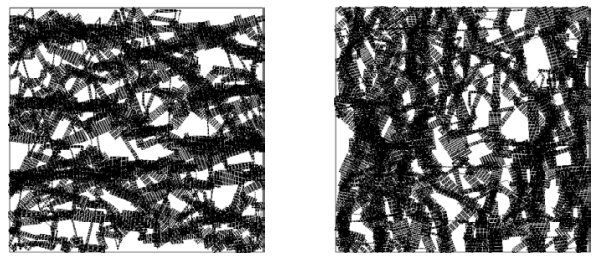

$\sigma_{\mathrm{x}}=0 \mathrm{MPa}$

$\sigma_{\mathrm{y}}=0 \mathrm{MPa}$
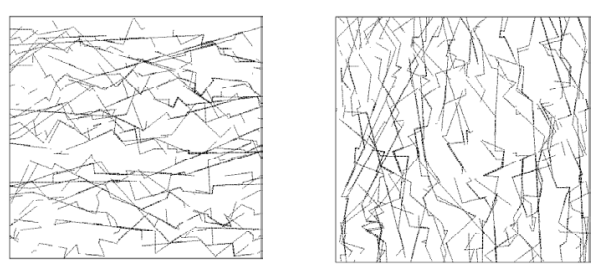

$\sigma_{\mathrm{x}}=5 \mathrm{MPa}$

$\sigma_{\mathrm{y}}=5 \mathrm{MPa}$
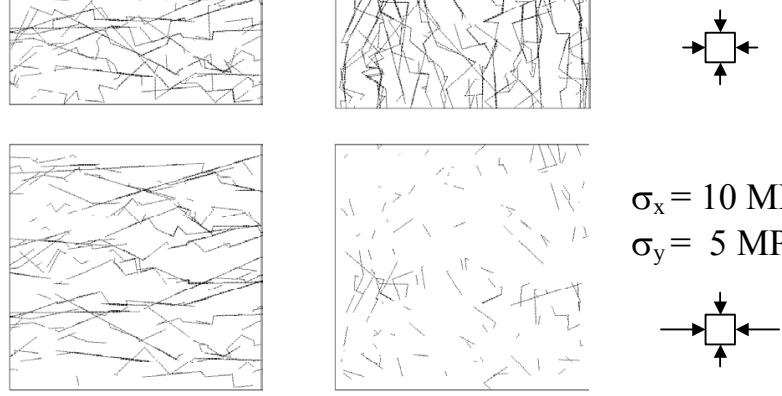

$$
\sigma_{\mathrm{x}}=10 \mathrm{MPa}
$$

$\sigma_{\mathrm{y}}=5 \mathrm{MPa}$
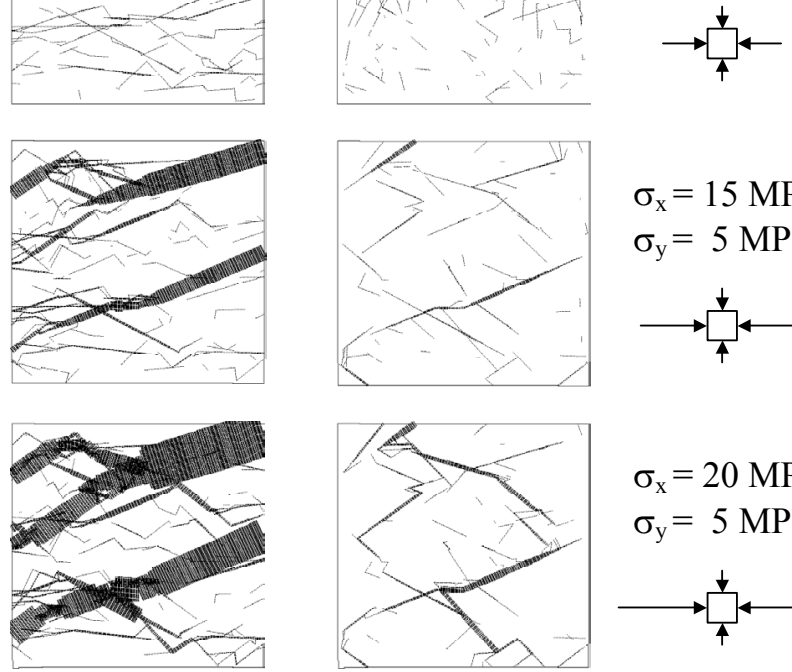

$$
\sigma_{\mathrm{x}}=20 \mathrm{MPa}
$$

$\sigma_{\mathrm{y}}=5 \mathrm{MPa}$

$\sigma_{\mathrm{x}}=15 \mathrm{MPa}$

$\sigma_{\mathrm{y}}=5 \mathrm{MPa}$

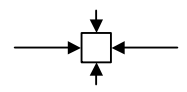

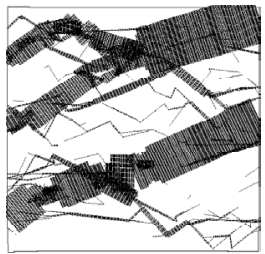

(a)

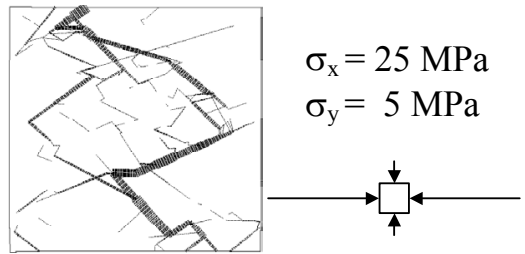

(b)

Figure 13. Fluid pathways during stress applications with the direction of hydraulic pressure gradient (a) from right to left, (b) from top to bottom. Thickness of the line represents the magnitude of flow rates. A thin line indicates the flow rate of $10^{-9} \mathrm{~m}^{3} / \mathrm{sec}$ and the flow rates smaller than this value are not drawn. 


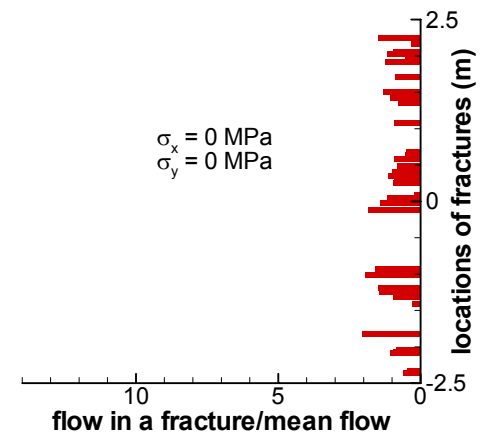

(a)

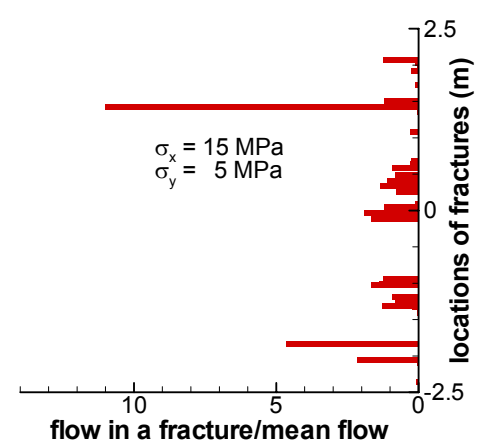

(d)

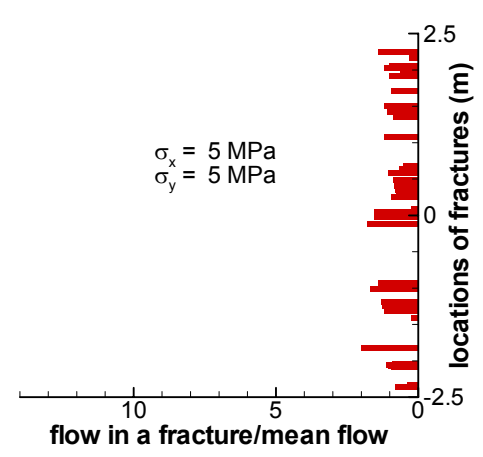

(b)

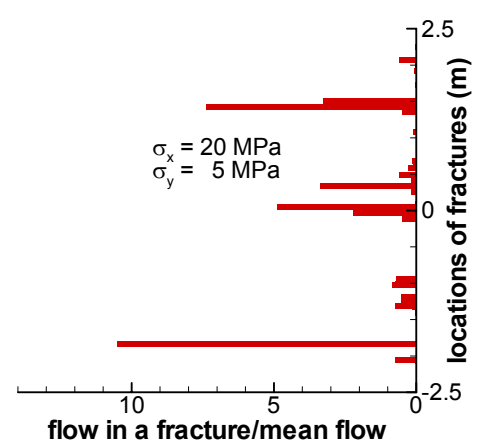

(e)

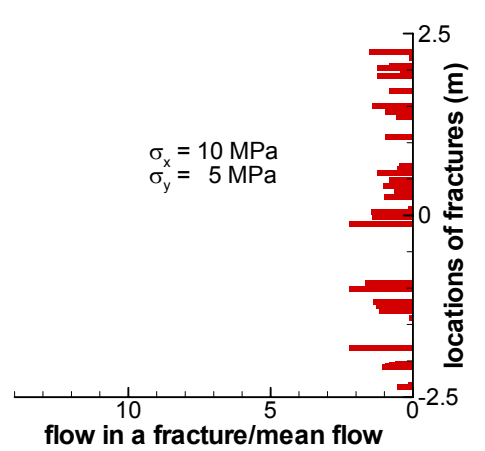

(c)

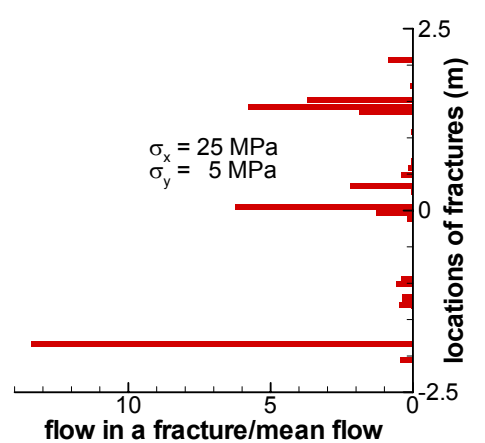

(f)

Figure 14. Normalized flow rates in each fracture intersecting the left vertical boundary of the model. (a) to (f) show the normalized flow rates in each stress step with varying stress ratio. 


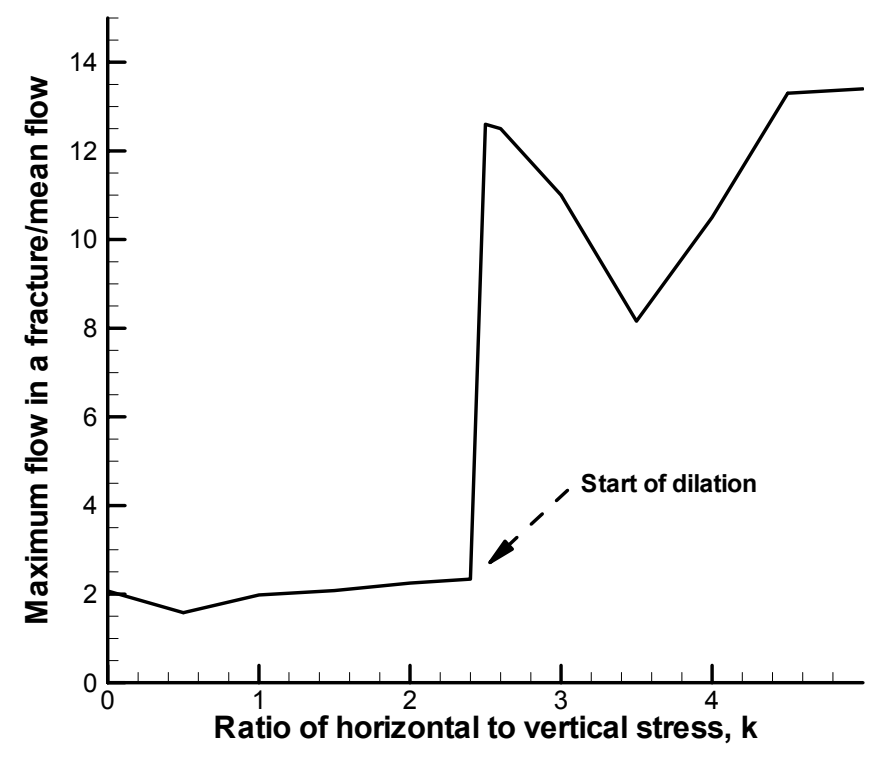

Figure 15. Maximum flow in a fracture divided by mean flow with the increase of stress ratio. 


\begin{tabular}{|c|c|c|c|c|}
\hline $\begin{array}{l}\text { Permeability in } \\
\text { fractured rock masses } \\
\qquad \begin{array}{c}k_{x}=k_{n x}+k_{d x} \\
k_{y}=k_{n y}+k_{d y}\end{array}\end{array}$ & $=$ & $\begin{array}{c}\text { Permeability from } \\
\text { Normal closure } \\
\qquad \begin{array}{c}k_{n x} \\
=\frac{f_{x}}{12} b_{x}{ }^{3} \\
k_{n y}=\frac{f_{y}}{12} b_{y}{ }^{3}\end{array}\end{array}$ & + & $\begin{array}{c}\text { Permeability from } \\
\begin{array}{c}\text { Shear dilation } \\
k_{d x}=\frac{f_{d x}}{12} d_{x}{ }^{3} \\
k_{d y}=\frac{f_{d y}}{12} d_{y}{ }^{3}\end{array}\end{array}$ \\
\hline
\end{tabular}

Figure 16. Components of the proposed empirical equations of stress-dependent permeability 


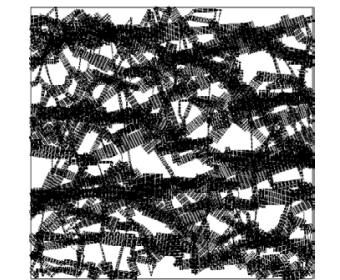

Fluid flow in DFN (no dilation)

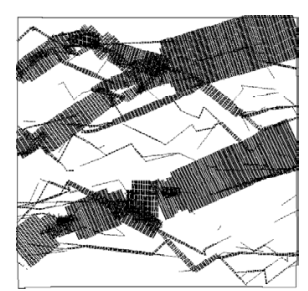

Fluid flow in DFN (with dilation)

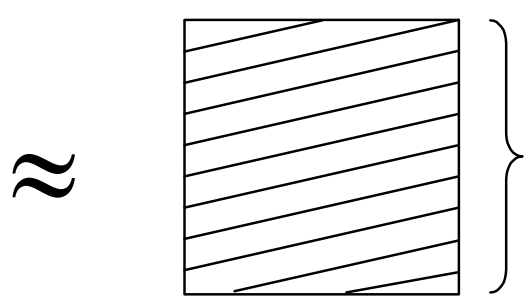

Equivalent fracture network (total)

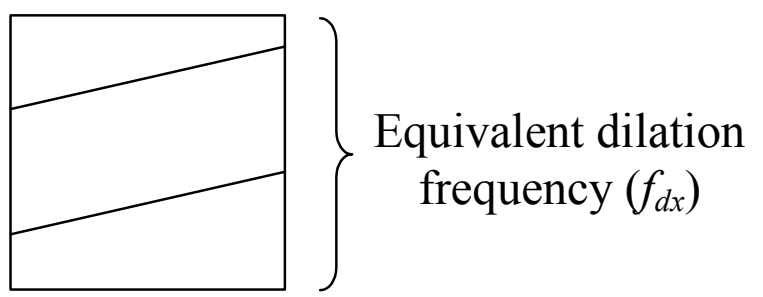

Equivalent fracture network (dilation)
Equivalent frequency $\left(f_{x}\right)$

Figure 17. Concept of equivalent frequency for fluid conducting fractures 


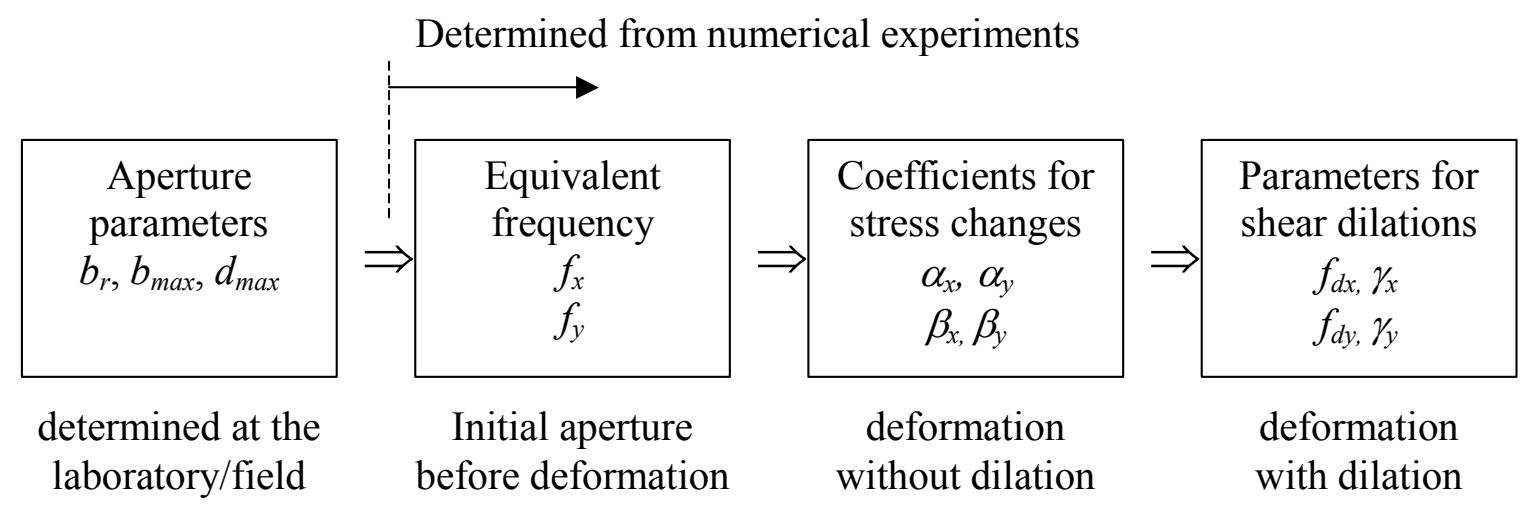

Figure 18 Procedure of determining the parameters for the proposed empirical equation. 

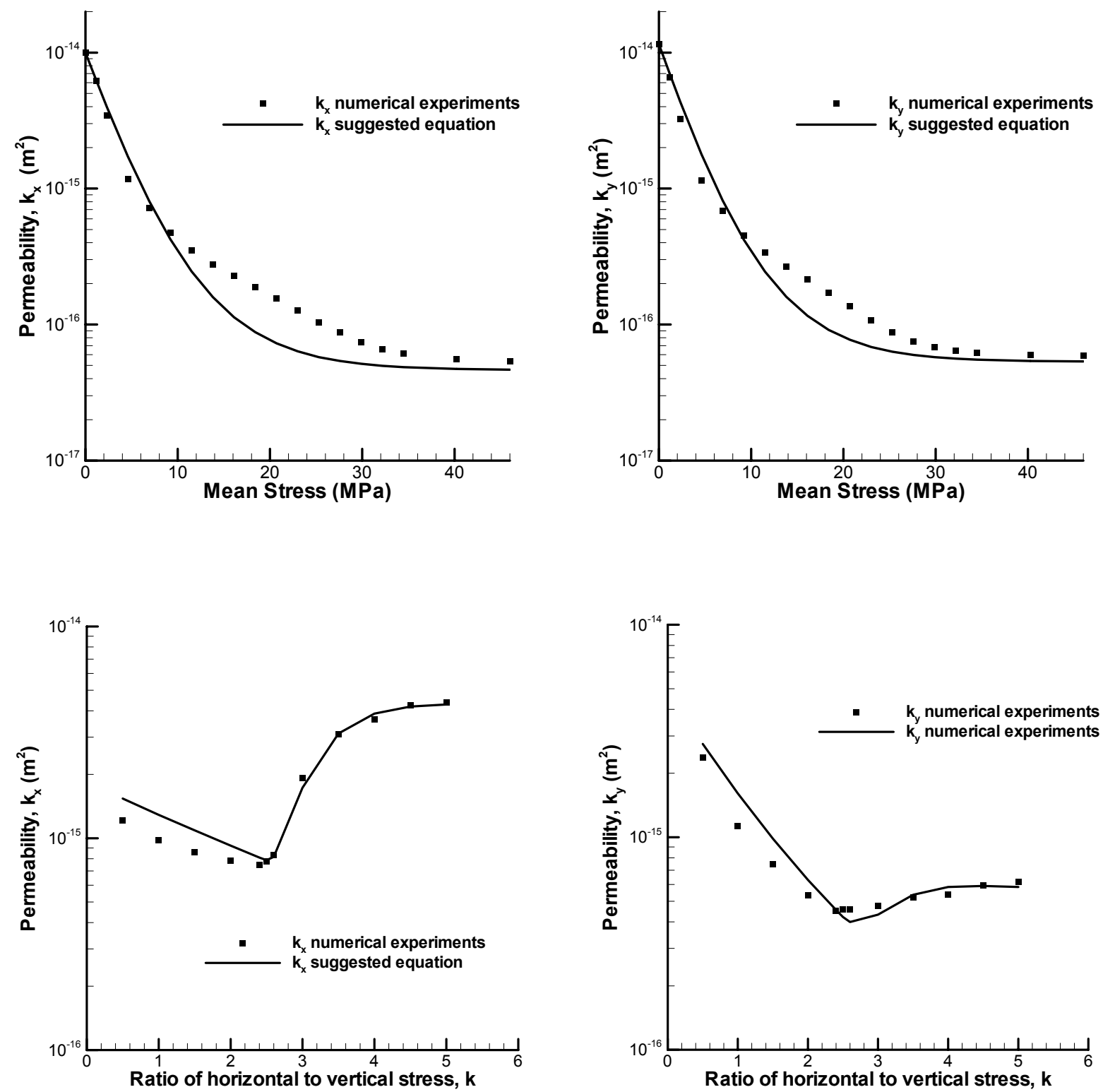

Figure 19. Comparison of equivalent permeabilities from numerical experiments and empirical equations 


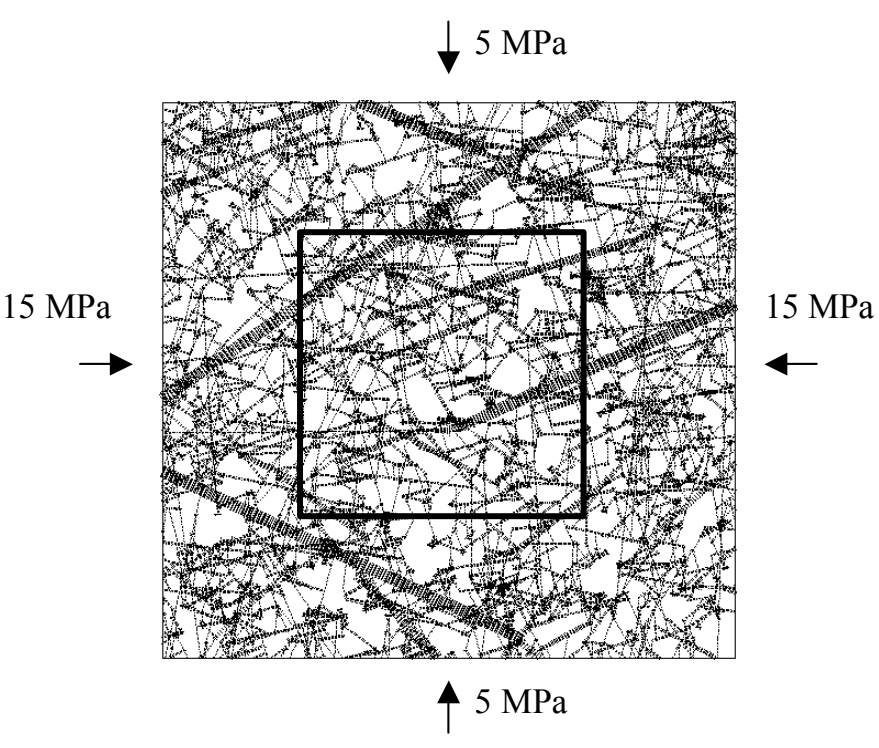

$10 \mathrm{~m} \times 10 \mathrm{~m}$ model

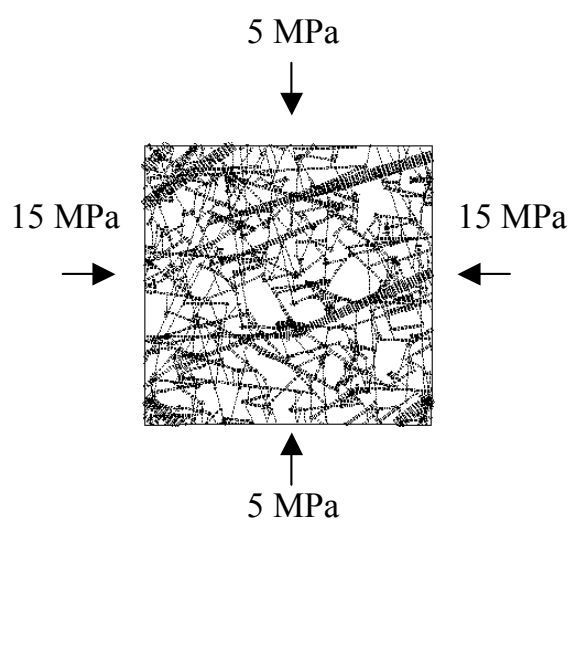

$5 \mathrm{~m} \times 5 \mathrm{~m}$ model

Figure 20. Investigation of boundary effect. Comparison is made between the resulting apertures of $10 \mathrm{~m} \times 10 \mathrm{~m}$ and $5 \mathrm{~m} \times 5 \mathrm{~m}$ models under the same stress boundary conditions. 